Article

\title{
Experimental Research on an Improved Slope Protection Structure in the Plunge Pool of a High Dam
}

\author{
Bin Ma ${ }^{1}$, Shuai Liang ${ }^{1}$, Chao Liang ${ }^{1, *}$ and ${\text { Yijia } \mathrm{Li}^{2}}^{2}$ \\ 1 State Key Laboratory of Hydraulic Engineering Simulation and Safety, Tianjin University, Tianjin 300072, China; \\ mabin97@tju.edu.cn (B.M.); liangshuai_ls@sina.cn (S.L.) \\ 2 School of Management, Tianjin University of Technology, Tianjin 300384, China; liyijia_tjut@126.com \\ * Correspondence: liangchao_0016@sina.cn; Tel.: +86-022-27406103
}

Received: 24 July 2017; Accepted: 31 August 2017; Published: 5 September 2017

\begin{abstract}
Due to impinging jets, the hydraulic load in a plunge pool can be very large and may cause serious damage to the slope and bottom protection structures. Conventional research mainly focuses on the stability of the plunge pool floor, and studies on slope protection safety are still lacking. Based on the Wudongde project, a physical model (that does not consider the plunge pool floor) was established. A series of experiments were conducted to investigate the protective measures for slope protection. Experimental results showed that the high seepage pressure on the back surface of the slope lining plate and poor correlation between the fluctuating pressures on both plate surfaces may cause large pressure differences that seriously threaten the stability of the slope lining plate. Therefore, a self-drainage slope protection structure was proposed to reduce the hydraulic load on a slope lining plate. It must be noted that the slope lining plate with the most violent water level fluctuation and adverse operating conditions (when the drainage system and part of the waterstops were invalid) were considered in the model tests. Test results indicated that self-drainage slope protection could enhance the synchronism of the pressure and water-level fluctuations on both plate surfaces. Therefore, the proposed slope protection structure could effectively reduce the total pressure on the plate and significantly increase the operational safety of the plunge pool.
\end{abstract}

Keywords: slope protection structure; self-drainage plate; seepage pressure; water surface fluctuations; correlation coefficient

\section{Introduction}

Large water conservancy projects in Southwest China are characterized by high head, tremendous flood discharge, and narrow valleys. Therefore, the dissipation of the tremendous energy generated in the flood discharge process is a difficult issue for such projects. The water turbulence in the plunge pool induced by impinging jets is extremely violent, which may cause damage to the protection structures [1-6]. Melo [7] pointed out that the failure of the waterstops at seal joints between different bottom slabs in plunge pools was a possible cause for the bottom destruction of water cushion pools. Liu [8] analyzed many practical examples on the destruction of protection structures in plunge pools and concluded that the pressure fluctuations generated by impinging jets were the primary reason for the slab failures during the flood discharge process. Tremendous uplift force can be induced due to the propagation of instantaneous pressure fluctuations through the drain system and the gaps between concrete slabs and bedrock. When the uplift forces exceed the sum of the anchoring and gravity forces of the lining slabs, the slabs will be dislodged and swept away.

To ensure the operational safety of a plunge pool, numerous studies have been undertaken on the stability of the concrete bottom plate in the water cushion pool. The propagation laws of the fluctuating pressure along the cracks and the failure mechanism of the bottom slab in plunge pools have been adequately studied by Rehbinder et al. [9], Zhao et al. [10], Li et al. [11], and Liu et al. [12]. The flow 
field characteristics of the arch-inverted plunge pool and flat-bottomed cushion pool were numerically simulated by Sun et al. [13]. Fiorotto et al. [14] studied the stability of the bottom plate in a plunge pool through theoretical analysis. Lian et al. [15] presented a comprehensive safety evaluation method for the protection structures in plunge pools, which further provided an important theoretical basis for the engineering design of counter-arched bottom slab. Yang et al. $[16,17]$ investigated the fluctuating pressure characteristics of the permeable plate and the experimental results showed that the pervious concrete slab could effectively reduce the uplift force. Zhang et al. [18] studied the load-reducing mechanisms of the pervious concrete slab based on the model test. Ma et al. [19,20] carried out a series of numerical simulations and model tests on slabs with key grooves where the results demonstrated that the key grooves could help to improve the ultimate resistance force and reduce the dynamic response of the slab. Castillo and Carrillo [21] studied the scour (due to the operation of the free surface spillway $\left(700 \mathrm{~m}^{3} / \mathrm{s}\right)$ and half-height outlets $\left.\left(1760 \mathrm{~m}^{3} / \mathrm{s}\right)\right)$ using three complementary procedures: empirical formulae obtained in models and prototypes, semi-empirical methodology based on the pressure fluctuations-erodibility index, and computational fluid dynamics simulations.

However, the existing research has mainly focused on the stability of bottom slabs in plunge pools and studies on the operational safety of the slope protection structure are rarely reported. Due to the reinforced concrete plate and anchorage measures, the slope protection stability is unlikely to be affected by the adverse effect of wave impact pressure and the erosion effect of water. However, high seepage pressure may be generated when the waterstop is invalid and drainage measures are necessary. This issue has already been considered by designers and engineers, thus the pump drainage system has been frequently applied in many projects, such as Xiluodu, Laxiwa, Xiaowan, Ertan, Jinping I, Nuozhadu, Xiangiaba, and so on [22]. There are two obvious disadvantages to the conventional pump drainage system: (i) the pump and drain pipe are prone to failure; and (ii) construction and operation costs are extremely high. The proposed slope protection structure in our study can effectively solve both of these problems.

In existing engineering projects, the bottom slab is directly impacted by the discharged flow and usually operates under worse working conditions than those of the slope protection structures. Therefore, the destruction of the bottom plates in plunge pools frequently occurs and accidents involving slope lining failure are less common. However, for some specific hydropower engineering projects, the downstream water cushion is very deep so natural plunge pools with a lining slope (but no bottom protection) are employed. In such cases, the operational safety of the bottom slab does not need to be considered so more attention should be paid to the study of the stability of the slope lining structure. Based on movable-bed scouring tests, Xu et al. [23] and Sun et al. [24] conducted feasibility studies for a plunge pool with a lining slope, but no bottom protection. Sun et al. [25] stated that a plunge pool with a lining slope but no bottom protection was feasible when the water cushion was deep and the bedrock sufficiently firm. Liu and $\mathrm{Li}$ [26] studied the development of scour pools due to jet impact downstream of high dams by considering hydrodynamic pressures and its propagation within rock cracks. Recently, the slope protection lining plates in the plunge pool of a large hydropower station were seriously damaged, therefore it is important and necessary to study the failure mechanisms and optimized structure for slope protection.

The shape of the slope lining plates in the natural plunge pool of the Wudongde project is similar to that of the natural mountain slope and the surfaces of most plates are irregular space curved faces. Moreover, the depth of the cushion in the plunge pool is approximately 108-121 m, and the bedrock in the energy dissipation area is firm and intact. According to the aforementioned conditions, a plunge pool with lining slope but no bottom protection is suitable for the Wudongde project and the stability of the slope lining is the key to the safety of the dam during the flood discharge. Once the waterstop is damaged, hydrodynamic pressure would propagate to the back side of the slope lining through the failed waterstop. Under certain conditions, the water level in the plunge pool goes down rapidly while the water seepage in the gaps between the slope lining slabs and the bedrock cannot be drained out in time, so high seepage and fluctuating pressure are great threats to slope plate stability. 
In this paper, overall hydraulic research was first conducted on the slope protection structure in the plunge pool. Next, the self-drainage protection structure is proposed and the experimental results show that self-drainage lining plates could enhance the synchronism of the fluctuating pressures on the back and front sides of the protection plate and better balance the hydraulic pressures on both sides of the lining slab than the drainage failure slope. Therefore, the proposed self-drainage slope protection can effectively reduce the pressure difference and significantly increase the operational safety of the hydraulic complex. Furthermore, the research presented in this paper provides theoretical support for the design of the slope protection plate and the safe operation mode of the water conservancy project.

\section{Establishment of the Physical Model}

\subsection{Similarity Theory for the Physical Model}

\subsubsection{Similarity Theory for the Fluctuating Pressure under Hydraulic Jumps}

The transient Navier-Stokes equations can be expressed as:

$$
\frac{\partial u_{i}}{\partial t}+u_{j} \frac{\partial u_{i}}{\partial x_{j}}=-\frac{1}{\rho} \frac{\partial p}{\partial x_{i}}+v \nabla^{2} u_{i}+X
$$

where $u, t$, and $\rho$ denote the flow velocity, time, and density of the water, respectively; $p, v$, and $x$ represent the pressure, kinematic viscosity, and spatial coordinate, respectively; $\nabla^{2}$ and $X$ denote the Laplace Operator and external mass force, respectively; the subscripts $i, j=1,2$ and 3 relate to variables in the $x, y$, and $z$ directions, respectively.

It is common to decompose the flow velocity and pressure into a time-average component $(\bar{u}, \bar{p})$ and a fluctuating component as $\left(u^{\prime}, p^{\prime}\right)$ as:

$$
\begin{aligned}
& u=\bar{u}+u^{\prime} \\
& p=\bar{p}+p^{\prime}
\end{aligned}
$$

Substituting Equations (2) and (3) into Equation (1), and then averaging the equation over time, the Reynolds equation for the time-average motion of water flow can be obtained:

$$
\frac{\partial \bar{u}_{i}}{\partial t}+\bar{u}_{j} \frac{\partial \bar{u}_{i}}{\partial x_{j}}=-\frac{1}{\rho} \frac{\partial \bar{p}}{\partial x_{i}}+v \nabla^{2} \bar{u}_{i}-\frac{\partial}{\partial x_{j}} \overline{u_{i}^{\prime} u_{j}^{\prime}}+X
$$

Substituting Equations (2)-(4) into Equation (1), the motion equation of the fluctuating flow can be expressed as:

$$
\frac{\partial u_{i}^{\prime}}{\partial t}+\bar{u}_{j} \frac{\partial u_{i}^{\prime}}{\partial x_{j}}+u_{j}^{\prime} \frac{\partial \bar{u}_{i}}{\partial x_{j}}=-\frac{1}{\rho} \frac{\partial p^{\prime}}{\partial x_{i}}+v \nabla^{2} u_{i}^{\prime}-\frac{\partial}{\partial x_{j}}\left(u_{i}^{\prime} u_{j}^{\prime}-\overline{u_{i}^{\prime} u_{j}^{\prime}}\right)
$$

Equations (4) and (5) describe the time-average and fluctuating motions of the water flow, respectively, and both the flow motions in the physical model and the prototype should satisfy these two equations.

The expressions for the scales of length $\left(\lambda_{l}\right)$, time-average velocity $\left(\lambda_{\bar{u}}\right)$, fluctuating velocity $\left(\lambda_{u^{\prime}}\right)$, time-average pressure $\left(\lambda_{\bar{p}}\right)$, fluctuating pressure $\left(\lambda_{p^{\prime}}\right)$, mass force $\left(\lambda_{X}\right)$, Reynolds stress $\left(\lambda_{\overline{u_{i}^{\prime} u_{j}^{\prime}}}\right)$, density $\left(\lambda_{\rho}\right)$ and time $\left(\lambda_{t}\right)$ can be given as follows:

$$
\left\{\begin{array}{c}
\lambda_{l}=l_{p} / l_{m} ; \quad \lambda_{\bar{u}}=\bar{u}_{p} / \bar{u}_{m} ; \quad \lambda_{u^{\prime}}=u_{p}^{\prime} / u_{m}^{\prime} ; \quad \lambda_{p^{\prime}}=p_{p}^{\prime} / p_{m}^{\prime} ; \quad \lambda_{\bar{p}}=p_{p}^{\prime} / p_{m}^{\prime} \\
\lambda_{X}=X_{p} / X_{m} ; \quad \lambda_{\overline{u_{i}^{\prime} u_{j}^{\prime}}}=\left(\overline{u_{i}^{\prime} u_{j}^{\prime}}\right)_{p} /\left(\overline{u_{i}^{\prime} u_{j}^{\prime}}\right)_{m} ; \quad \lambda_{\rho}=\rho_{p} / \rho_{m} ; \quad \lambda_{t}=t_{p} / t_{m}
\end{array}\right.
$$


where the subscripts $p$ and $m$ relate to the variables of the prototype and the physical model, respectively.

For the time-average motion of the water flow in prototype, Equation (4) can be rewritten as:

$$
\begin{aligned}
\frac{\lambda_{\bar{u}}}{\lambda_{t}} \frac{\partial\left(\bar{u}_{i}\right)_{m}}{\partial t_{m}}+\lambda_{\bar{u}}\left(\bar{u}_{j}\right)_{m} \frac{\lambda_{\bar{u}}}{\lambda_{l}} \frac{\partial\left(\bar{u}_{i}\right)_{m}}{\partial\left(x_{j}\right)_{m}} & \\
= & -\frac{1}{\lambda_{\rho} \rho_{m}} \frac{\partial \bar{p}_{m}}{\partial\left(x_{i}\right)_{m}}+\lambda_{v} v_{m} \frac{\lambda_{\bar{u}}}{\lambda_{l}^{2}} \nabla^{2}\left(\bar{u}_{i}\right)_{m}-\frac{\lambda_{\overline{u_{i}^{\prime} u_{j}^{\prime}}}}{\lambda_{l}} \frac{\partial}{\partial\left(x_{i}\right)_{m}}\left(\overline{u_{i}^{\prime} u_{j}^{\prime}}\right)_{m}+\lambda_{g} X_{m}
\end{aligned}
$$

Moreover, the Reynolds equation for the time-average motion of the water flow in the physical model can be expressed as

$$
\frac{\partial\left(\bar{u}_{i}\right)_{m}}{\partial t_{m}}+\left(\bar{u}_{j}\right)_{m} \frac{\partial\left(\bar{u}_{i}\right)_{m}}{\partial\left(x_{j}\right)_{m}}=-\frac{1}{\rho_{m}} \frac{\partial \bar{p}_{m}}{\partial\left(x_{i}\right)_{m}}+v_{m} \nabla^{2}\left(\bar{u}_{i}\right)_{m}-\frac{\partial}{\partial\left(x_{i}\right)_{m}}\left(\overline{u_{i}^{\prime} u_{j}^{\prime}}\right)_{m}+X_{m}
$$

Comparing Equation (7) with Equation (8), the following formula is obtained according to the kinematic similarity conditions

$$
\frac{\lambda_{l}}{\lambda_{\bar{u}} \lambda_{t}}=\frac{\lambda_{v}}{\lambda_{\bar{u}} \lambda_{l}}=\frac{\lambda_{\bar{p}}}{\lambda_{\rho} \lambda_{\bar{u}}^{2}}=\frac{\lambda_{\overline{u_{i}^{\prime} u_{j}^{\prime}}}}{\lambda_{\bar{u}}^{2}}=\frac{\lambda_{g} \lambda_{l}}{\lambda_{\bar{u}}^{2}}=1
$$

According to Equation (9), it is not difficult to draw the conclusion that the Strouhal numbers (St), Euler numbers $(E u)$, Reynolds numbers $(R e)$, turbulent coefficients $(N)$, and Froude numbers $(F r)$ for the water flows in both the prototype and physical model should be equal to each other when the kinematic similarity conditions are satisfied.

On the basis of Equation (5), the following formula describing the kinematic similarity conditions for the fluctuating motion of turbulent flow can be obtained in a similar way as the deduction of Equation (9).

$$
\frac{\lambda_{l}}{\lambda_{\bar{u}} \lambda_{t}}=\frac{\lambda_{p^{\prime}}}{\lambda_{u^{\prime}} \lambda_{\bar{u}} \lambda_{\rho}}=\frac{\lambda_{v}}{\lambda_{l} \lambda_{\bar{u}}}=\frac{\lambda_{u^{\prime}}}{\lambda_{\bar{u}}}=\frac{\lambda_{\overline{u_{i}^{\prime} u_{j}^{\prime}}}}{\lambda_{\bar{u}} \lambda_{u^{\prime}}}=1
$$

It is noted that a new equation $\left(\lambda_{u^{\prime}} / \lambda_{\bar{u}}=1\right)$ is introduced by the similarity conditions between the fluctuating motions of the water flows in the prototype and physical model. According to the newly introduced equation, it is found that the Kármán numbers (Ka) for the water flows in the prototype and physical model should be equal to each other so that the kinematic similarity conditions can be satisfied.

It is known that the parameters $E u, K a$, and $N$ are the functions of $R e$ and $F r$. Therefore, for the water flow in the region of quadratic resistance law, the necessary and sufficient conditions of the kinematic similarity are that: (1) the geometric and boundary conditions of the physical model are similar to the prototype; and (2) the parameters $R e$ and $F r$ for the model flow are equal to the prototype flow. Based on condition (2), the following equations can be obtained [27].

$$
\lambda_{p^{\prime} / \gamma}=\lambda_{l} ; \quad \lambda_{f}=\lambda_{l}^{-0.5}
$$

where $\lambda_{p^{\prime} / \gamma}$ and $\lambda_{f}$ denote the scales of the fluctuating pressure amplitude and frequency.

It is noted that the relationship described by Equation (11) is exactly the gravity similarity law. Additionally, the gravity similarity law or Froude similarity is also applicable to the physical model simulation of the smooth flow. As the water in the plunge pool usually fluctuates violently during the flood discharge process, a detailed discussion for the similarity criterion of the smooth flow is not included in the present paper. 


\subsubsection{Similarity Theory for the Fluctuating Pressure Induced by the Flow in Gaps}

During the flood discharge process, the water in the plunge pool seeps into cracks between the concrete lining slabs on the slope or at the bottom of the cushion pool and the bedrock, which has a significant influence on the stability of the slope and bottom lining plates. Pressure propagation in fissured media is a difficult problem and many studies have investigated this issue. Rehbinder [28] stated that the flow motion in the rock fracture obeyed Darcy's law and that fluctuating pressure was transmitted at the speed of flow motion; when the hydraulic pressures exceed the threshold, the rocks gradually disintegrate. Zhao and Liang [10] stated that hydrodynamic pressure acting on two sides of the crack will generate crack water oscillation, which is the main cause of the fluctuating pressure. Fiorotto and Rinaldo [29] pointed out that the safe design of protection works was significantly affected by the structure of instantaneous spatial distribution of pressure at the bottom of hydraulic jumps, and that fluctuating pressure was transmitted in the form of waves and was independent of flow velocity. Liu et al. [30] deduced a predicting formula for the maximum fluctuating uplift on rock blocks in a scour pool on the basis of the transient flow model. Manso et al. [31] presented their experimental investigations in plunge pools with different lateral confinement with results that showed that pool geometry influenced plunging jet diffusion, and air entrainment in the pool, and consequently, impact pressures at the water-rock interface and inside the fissured rock mass.

In the physical model test, the similarity criterion for crack flow needs to be considered in the physical model simulation and the crack width in the physical model should be determined according to the similarity condition. It is noted that the widths of cracks between the lining plates and bedrock in the prototype are quite narrow so that the aforementioned approach to reduce the crack width according to the length scale $\lambda_{l}$ in the physical model is not feasible. Furthermore, based on the theoretical analysis given as follows, applying the aforementioned approach to simulate crack width is theoretically incorrect.

In a narrow crack, the viscous force will significantly influence the motion of fluid as well as the distribution of fluctuating pressure. Due to the complexity for the motion of crack flow, the similarity criterion for crack flow in the physical model simulation is a controversial issue. If we consider the crack flow as the laminar flow along $x$ direction, the N-S equation can be reduced to the following form.

$$
X_{1}-\frac{1}{\rho} \frac{\partial p}{\partial x_{1}}+v\left(\frac{\partial^{2} u_{1}}{\partial x_{2}^{2}}+\frac{\partial^{2} u_{1}}{\partial x_{3}^{2}}\right)=0 ; \quad X_{2}-\frac{1}{\rho} \frac{\partial p}{\partial x_{2}}=0 ; \quad X_{3}-\frac{1}{\rho} \frac{\partial p}{\partial x_{3}}=0
$$

It is common to consider that the velocity $u_{1}$ remains unchanged along the $z$ direction, therefore the motion equation for the constant and uniform flow of the incompressible viscous fluid can be expressed as:

$$
\frac{\partial^{2} u_{1}}{\partial x_{2}^{2}}=-\frac{\gamma J}{\mu}
$$

where the parameters $\gamma, \mu$, and $J$ denote the unit weight, dynamic viscosity coefficient, and cross-section area, respectively.

Considering the boundary conditions, the average velocity of the cross-section $v$ can be calculated by integrating the velocity $u_{1}$ over the crack width and the calculation formula is given as follows.

$$
v=\frac{1}{2 d} \int_{-d}^{d} u_{1} d x_{2}=\frac{1}{2 d} \int_{-d}^{d} \frac{\gamma J}{2 \mu}\left(d^{2}-x_{2}^{2}\right) d x_{2}=\frac{1}{2 d}\left[\int_{-d}^{d} \frac{\gamma J}{2 \mu} d^{2} d x_{2}-\int_{-d}^{d} \frac{\gamma J}{2 \mu} x_{2}^{2} d x_{2}\right]=\frac{\gamma J}{3 \mu} d^{2}
$$

where $d$ denotes the width of the crack.

Therefore, the relationship of the crack width scale and the length scale is obtained.

$$
\lambda^{*}=\sqrt[4]{\lambda_{l}}
$$


For the frequently used length scale in the physical model simulation $\lambda_{l}=100$, and the crack width scale $\lambda^{*}=3.16$, which indicates that the crack width value in the physical model had the same order of magnitude as that in the prototype. This conclusion provides a more realistic theoretical basis for the physical model simulation where the effect of crack flow cannot be neglected, and the application scope of the physical model analysis approach is greatly expanded. Moreover, similar physical model simulations are widely applied to conduct the practical construction of many water conservancy and hydropower projects, and the engineering practice indicates that the experimental results are approximately equal to those of the prototype tests. The data accuracy of the physical model experiment satisfies the requirements of the actual engineering project [22].

\subsection{Basic Information on the Physical Model}

Wudongde Dam, located in the lower reach of the Jinsha River, is a concrete double-curvature arch dam. The elevations of the foundation surface and dam crest are 718 and $988 \mathrm{~m}$ above sea level, respectively, and the maximum height of the dam is $270 \mathrm{~m}$. Moreover, the normal water level, design flood level, and check flood level are $975,979.38$ and $986.17 \mathrm{~m}$, respectively. The installed capacity is $10,200 \mathrm{MW}$ and $389,300 \mathrm{GWh}$ is produced per year. To discharge a flood with a peak flow of $35,800 \mathrm{~m}^{3} / \mathrm{s}$ in the wet season, five surface orifices and six mid-level outlets were designed on the dam body and three spillway tunnels were excavated on the left bank. The energy dissipator of Wudongde Hydropower Station is a natural plunge pool with a lining slope, but no bottom protection, and the subsidiary dam lies at the end of the plunge pool.

The model test was designed based on the Froude similarity criterion or gravity criterion and the geometric scale $\lambda_{l}$ was 100 . Moreover, the simulation objects mainly included the arch dam, plunge pool, subsidiary dam, and a section of the upstream channel. The bedrock of the slope and bottom in the plunge pool were made of Plexiglass and the slope lining slabs were gray plastic plates. Furthermore, according to the theoretical analysis in Section 2.1.2, the widths of the gaps (if it had to be considered) between the bedrock and slope lining plate were $0.2 \mathrm{~mm}$.

The intersection point of the surface outlet weir crest and the flood discharge center line was defined as the point of reference number $0+00 \mathrm{~m}$, and the reference number increased as the point moved downstream. Moreover, the length of the plunge pool was approximately $300 \mathrm{~m}$ and its bottom elevation $732 \mathrm{~m}$. It was noted that the slope in the plunge pool was divided into five layers by the berms, and the elevations of the berms were $767,797,827,857$ and $870.5 \mathrm{~m}$ above sea level, respectively.

To extrapolate the model test results to those of the prototype, the scale effect between the physical model and prototype should be carefully considered. It is known that the similarity between the turbulent flow motions in the physical model and prototype requires both similarities for the time-average and fluctuating motions. According to the above analysis, as long as the Froude similarity criterion (or gravity criterion) is satisfied, the time-average and fluctuating motions (as well as the turbulent motion) in the model test are respectively similar to the motions in the prototype in the region of quadratic resistance law. Moreover, it is easy to conclude from Equation (10) that the similarity law for the fluctuating pressure was also satisfied. However, the similarity law for the air entrainment of the discharge jet influenced by the surface tension and turbulence effects was difficult to be considered quantitatively. It can be seen from Figures 1 and 2 that the aeration conditions between the physical model and prototype are quite different from each other, which leads to an important scale effect. Many researchers have studied in detail the scale effect due to aeration and some beneficial conclusions have been obtained. Ervine and Falvey [32] studied jet diffusion in the plunge pool by considering the difference between submerged and impinging jets, the role of inner core decay for impinging jets, the effect of entrained air on the reduction of impact pressures, and the pressure fluctuations caused by turbulence in the plunge pool shear layers. Ervine et al. [33] studied the pressure fluctuation field on a plunge pool floor subjected to jet impingement and also considered the effects of the degree of break-up of the jet before it enters the basin and the air entrainment in the plunge pool. Bollaert and Schleiss [34] presented state-of-the-art methods to estimate rock scour 
due to the impingement of plunging high velocity water jets and found that the lack of knowledge on turbulence and aeration effects may significantly reduce the accuracy of existing scour evaluation methods. Bollaert and Schleiss [35] studied pool bottom pressures inside rock joints and pointed out that a reasonable consideration of the interaction between air and water was key for a better assessment of scour formation in rock. Manso et al. [36] investigated the influence of supply circuit secondary currents, aeration, and geometrical contraction on jet turbulence intensity and velocity profiles. Castillo and Carrillo [37] measured the aeration rates by means of fiber optical equipment, velocities in different sections of the stilling basin with Doppler instrumentations, and pressures on the bottom of the plunge pool with piezo-resistive transducers to improve the knowledge of the phenomenon of turbulent jets. Castillo et al. [38,39] comprehensively investigated the laboratory data on pressures, velocities, and air entrainment, and studied the impinging jets in plunge pools from overflow nappe flows on the basis of the physical model test and numerical simulation techniques. In their study, the scale effect caused by the dissimilarity of air entrainment in the physical model test was discussed in detail. For the physical model tests in this study, it is necessary to point out that the aeration similarity issue was not taken into consideration, which led to higher model pressure than the prototype. Therefore, the experimental results (the water level and pressure fluctuation) were likely to be oversized and the results will be on the safe side.

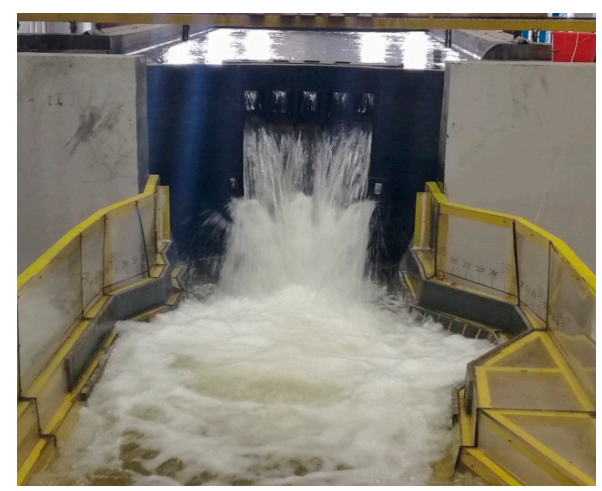

Figure 1. A photograph of the physical model test of the Wudongde arch dam.

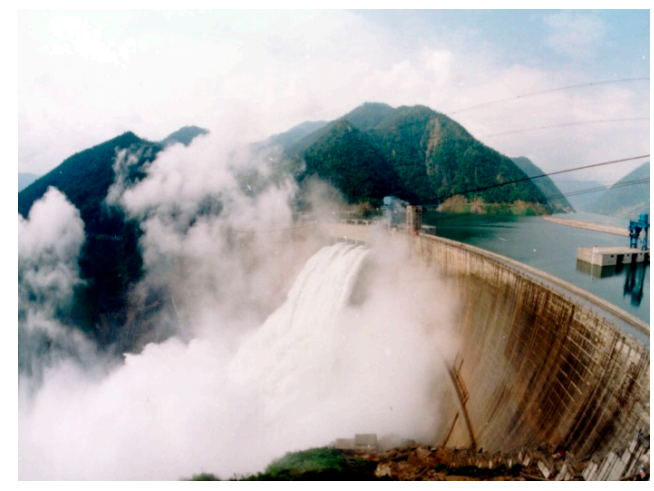

Figure 2. A flood discharge photograph of the Ertan arch dam.

According to the above-mentioned analysis, the larger the model scale, the smaller the difference between the physical model and prototype, so that the scale effect will be smaller and the experimental data will be more accurate. In Table 1, the physical models involved in the references and their basic information including the corresponding engineering project, the simulated hydraulic structure, the tested data, and the length scale are listed. It was noted that a relatively high length scale 1:100 was applied in many other physical model tests to measure fluctuating pressure, uplift force, scour depth, 
and so on. Based on engineering practice, the relatively high length scale 1:100 can satisfy the actual requirements of an engineering project and can significantly decrease construction costs.

Table 1. Basic information of the physical models involved in the references.

\begin{tabular}{|c|c|c|c|c|c|}
\hline No. & Engineering Project & Hydraulic Structure & Tested Data & Length Scale & Reference \\
\hline 1 & Karnafuli project & Spillway chute & Fluctuating pressure. & $1: 60 ; 1: 132$ & [2] \\
\hline 2 & Three-Gorges project & Spillway dam & Fluctuating pressure; uplift force. & 1:100 & [8] \\
\hline 3 & Laxiwa project & Plunge pool floor & $\begin{array}{l}\text { Fluctuating pressure; uplift force; } \\
\text { Impinging pressure; thrust at springer. }\end{array}$ & $1: 100$ & [15] \\
\hline 4 & Dukouba project & Plunge pool floor & Fluctuating pressure; uplift force. & $1: 50$ & [17] \\
\hline 5 & Laxiwa project & Plunge pool floor & Fluctuating pressure; uplift force. & $1: 100$ & [18] \\
\hline 6 & Xiangjiaba project & Plunge pool floor & Fluctuating pressure; uplift force. & $1: 80$ & [20] \\
\hline 7 & Paute-Cardenillo project & Downstream site of the dam & Fluctuating pressure; scour depth. & $1: 50$ & [21] \\
\hline 8 & Nuozhadu project & Downstream site of the dam & Fluctuating pressure; scour depth. & $1: 100$ & [23] \\
\hline 9 & Xiaowan project & Downstream site of the dam & Fluctuating pressure; scour depth. & $1: 120$ & [24] \\
\hline 10 & Songta project & Downstream site of the dam & Fluctuating pressure; scour depth. & $1: 100$ & [25] \\
\hline 11 & - & Water channel & Fluctuating pressure. & $1: 1 ; 1: 2 ; 1: 3 ; 1: 5$ & [27] \\
\hline 12 & $\begin{array}{l}\text { Xiluodu, Laxiwa, Jinping } \\
\text { I, Nuozhadu and } \\
\text { Xiangjiaba projects }\end{array}$ & $\begin{array}{l}\text { Bottom and slope plates of } \\
\text { Plunge pools }\end{array}$ & Fluctuating pressure; uplift force. & 1:100 & [22] \\
\hline 13 & Morrow Point project & Plunge pool & Flow regime; jet diffusion; flow velocity. & $1: 24$ & [32] \\
\hline 14 & - & Plunge pool & $\begin{array}{l}\text { Impingement velocity; hydraulic } \\
\text { pressure. }\end{array}$ & $1: 1 ; 1: 10 ; 1: 20 ; 1: 40$ & [37] \\
\hline
\end{tabular}

\section{Experimental Research on the Fluctuating Pressure Measured on the Slope Lining Plates in Plunge Pools}

\subsection{Experimental Scheme}

Considering integrally the large slope lining area, the quantitative limitation of sensors, and the position where the jet enters the water cushion in the plunge pool, 36 fluctuating pressure sensors were installed to measure time-average and fluctuating pressures on the slope lining plates, and the sensor distribution is illustrated in Figure 3. The reference numbers $0+155,0+175,0+245$ and $0+$ $325 \mathrm{~m}$ on the left slope and $0+135,0+175,0+195,0+215,0+245$ and $0+325 \mathrm{~m}$ on the right slope, respectively, were chosen for the sensor arrangement. For most reference numbers, four sensors were installed in the middle elevation of four lower slope layers, respectively, and the elevations of different berms and the fluctuating pressure sensors on different slope layers are illustrated in Figure 4.

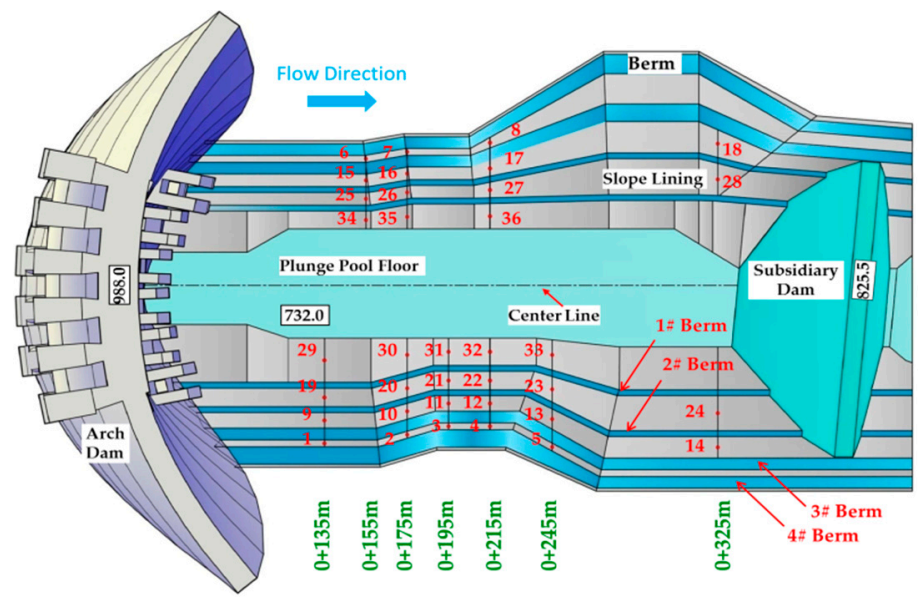

Figure 3. Arrangement of the fluctuation pressure sensors on the slope lining plate in the plunge pool. 


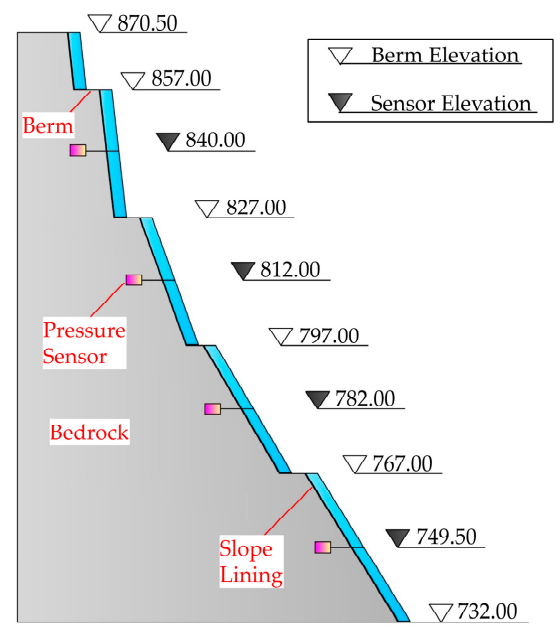

Figure 4. Elevations of berms and sensors on different slope layers.

The constitution of the pressure sensors and its manufacturer, type, precision, and other detailed performance parameters are given in Figure 5. Moreover, an electromagnetic flowmeter and a homemade rectangular thin-plate weir were installed in the water inlet and the downstream discharge channel, respectively, of the physical model to measure the discharge of the physical model. The precision of the electromagnetic flowmeter was approximately $6.9 \times 10^{-4} \mathrm{~m}^{3} / \mathrm{s}$, and the values of the flow rates obtained from the two aforementioned instruments were very close to each other.

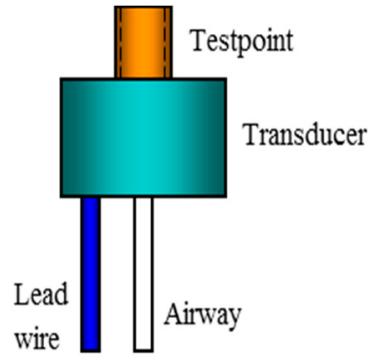

(a)

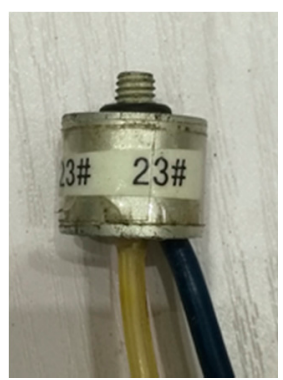

(b)
Manufacturer: China Institute of Water

Resources and Hydropower Research

Sensor type: Silicon piezo-resistive sensor

Precision: $0.01 \mathrm{kPa}$

Measurement error: $\leq \pm 0.5 \%$ F.S.

Full-scale (F.S.): 0-30 kPa

Acquisition frequency: $200 \mathrm{~Hz}$

Acquisition time: $100 \mathrm{~s}$

(c)

Figure 5. Constitution and performance parameters for the pressure sensor. (a) sensor components; (b) actual photograph; and (c) performance parameters.

It is noted that the acquisition frequency of the pressure transducer is relatively low. Considering the scale effect on pressure fluctuations, the highest measurable frequency of the pressure fluctuation in prototype scale is $20 \mathrm{~Hz}$. According to the characteristic studies of fluctuating pressure in both the physical model test and the prototype test, the dominant frequencies of the fluctuating pressure histories generated by the supercritical flow, the hydraulic jump, and the turbulent flow in rolling motion in the plunge pool are generally lower than $2 \mathrm{~Hz}$ and rarely exceed $5 \mathrm{~Hz}[17,18,20,22,27]$. The energy of relatively high frequency components is very small and can be ignored. Therefore, the pressure transducer with a $200 \mathrm{~Hz}$ acquisition frequency is frequently used in physical model experiments [17,18,20,22,27] and is generally considered to be applicable when measuring the fluctuating pressure in the plunge pool in a model test. Moreover, it is believed by some researchers that the fluctuating pressure generated by the supercritical flow may consist of relatively high-frequency components $[22,27]$, and the detailed dynamic characteristics for the supercritical flow pressure fluctuation should be further investigated using pressure transducers with a higher acquisition frequency.

During the operation process of the hydropower station, the energy generated by the discharge flow varies with the flood discharge, upstream water elevation, and the opening mode of the outlets. 
First, the fluctuating and time-average pressure histories were collected and analyzed for more than 20 different working conditions. To avoid redundancy, only the analysis for the experimental results of the two representative operating conditions given in Table 2 is included in this paper. Moreover, the fluctuating and time-average pressures measured under other operation conditions were lower than those measured in the two representative conditions and the detailed analysis for the test results of the other 18 working conditions have not been included in this article.

Table 2. Operating conditions.

\begin{tabular}{|c|c|c|c|c|c|}
\hline \multirow[b]{2}{*}{ Case } & \multirow[b]{2}{*}{ Upstream Water Level (m) } & \multirow[b]{2}{*}{ Flood Discharged from Dam Body $\left(\mathrm{m}^{3} / \mathrm{s}\right)$} & \multirow[b]{2}{*}{ Downstream Water Level (m) } & \multicolumn{2}{|c|}{ Opening Outlets } \\
\hline & & & & Surface Outlets & Mid-Level Outlets \\
\hline 1 & 979.38 & $20,186.0$ & 849.73 & 1\#2\#3\#4\#5\# & 1\#2\#3\#4\#5\#6\# \\
\hline 2 & 975 & $16,421.5$ & 847.86 & 1\#2\#3\#4\#5\# & $1 \# 2 \# 3 \# 4 \# 5 \# 6 \#$ \\
\hline
\end{tabular}

To explain the rationality for the selection of the typical working conditions, all of the operating conditions involved in the model tests are provided in Appendix A. It was noted that the flow discharges in the chosen working conditions (Conditions 1 and 2) were obviously larger than those in other working conditions. Therefore, under the representative operating conditions, the energy that needs to be dissipated in the plunge pool is much larger, and the safety requirements for the dam operation much stricter. According to research by Lian et al. [15], Yang and Li [17], Ma and Yue [20], Yang [22], Xu et al. [23] and Liu [27], it was observed that the safety operation for the working conditions with small flow rates could be guaranteed as long as the safety requirements of the working conditions with large flow rates were satisfied. Therefore, the first two working conditions in Appendix A were selected as the typical working conditions for detailed analysis.

\subsection{Experimental Data Analysis}

\subsubsection{Time-Average Pressure}

Figures 6 and 7 show the time-average hydraulic pressures measured at different test points under operating Conditions 1 and 2. According to the test results, hydrostatic pressure accounted for the main portion of the time-average hydraulic pressure and the difference between the time-average pressures measured at test points with different reference numbers and same elevations was quite small. Moreover, the maximum pressure difference between test points on the same elevation was $39.2 \mathrm{KPa}$ and the pressure difference was mainly caused by water level fluctuations. It was noted that the pressures measured at the test points near the subsidiary dam were slightly larger than those measured at the upstream test points in many cases. The main reason was probably that the flow was blocked in front of the subsidiary dam so that the water depth was slightly increased. 


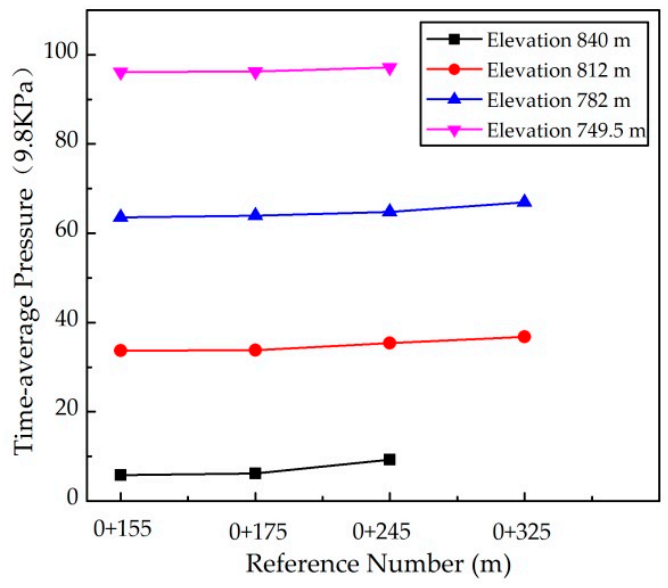

(a)

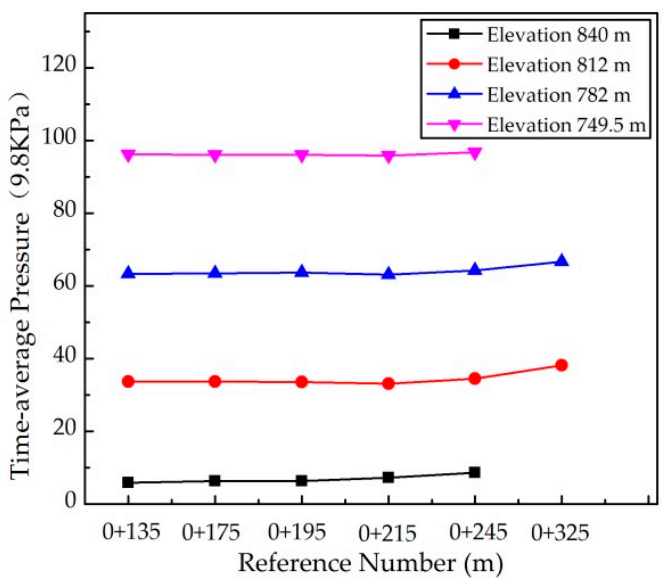

(b)

Figure 6. The distribution of Time-average pressures on the slope lining under operating Condition 1. (a) left slope; and (b) right slope.

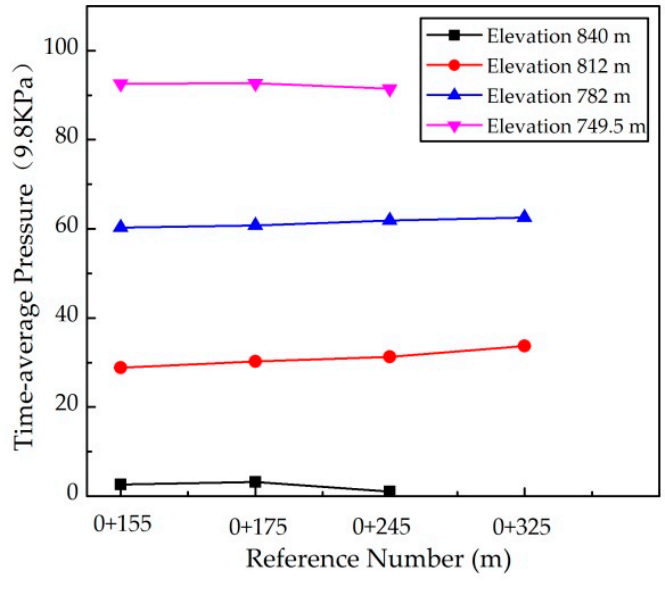

(a)

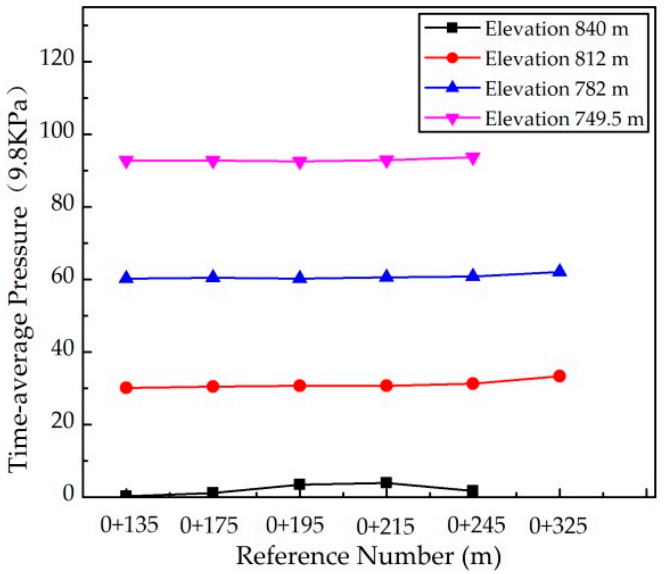

(b)

Figure 7. Time-average pressures on the slope lining plates under operating Condition 2. (a) left slope; and (b) right slope.

\subsubsection{Fluctuating Pressure}

The root mean squares (RMSs) of fluctuating pressures measured at different test points under working Conditions 1 and 2 are illustrated in Figures 8 and 9. Considering the test results of both operating conditions, the maximum value of the fluctuating pressure RMSs (denoted as $\sigma_{\max }$ ) was $15.29 \mathrm{KPa}$, which was observed in Condition 1 when the flood for safety-checking was considered. Under other operating conditions with a relatively large flood discharge, the fluctuating pressure RMSs of most test points were lower than $9.8 \mathrm{KPa}$ and in small flood discharge conditions, most RMS values were lower than $4.9 \mathrm{KPa}$. When comparing the fluctuating pressure RMSs of the same test point under different conditions, it was noted that the RMS value increased with increases to the flood discharged from the dam body, which conformed to common knowledge.

Due to the very deep water cushion in the plunge pool, the flow discharged from the dam body does not directly impact the bottom of the water cushion pool, therefore the transverse eddies were not fully developed. The energy was greatly dissipated by jet diffusion in the surrounding water so the fluctuating pressure on the slope lining plates was quite low. 


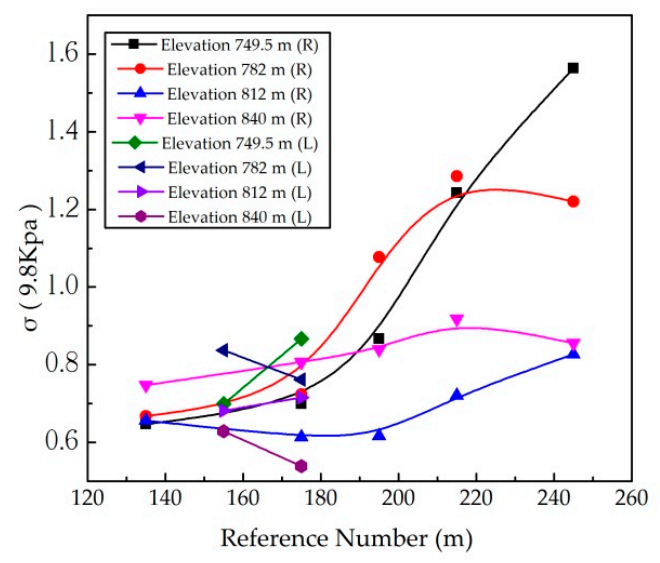

(a)

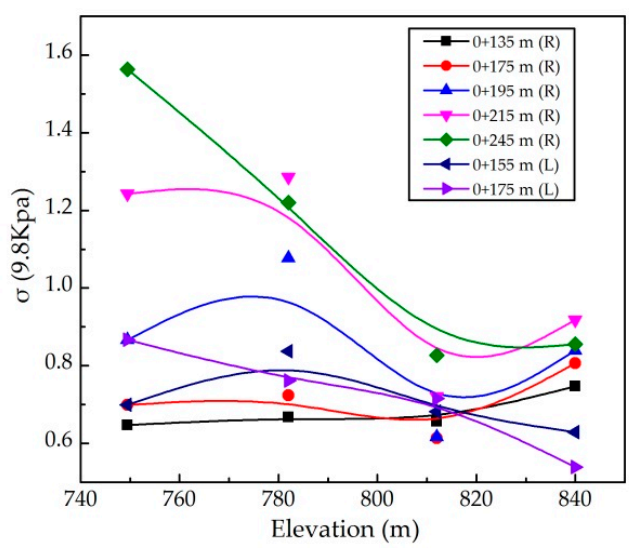

(b)

Figure 8. The RMS values $\sigma$ of fluctuating pressure histories on slope protection plates under operating Condition 1. (a) along reference numbers; and (b) along elevation.

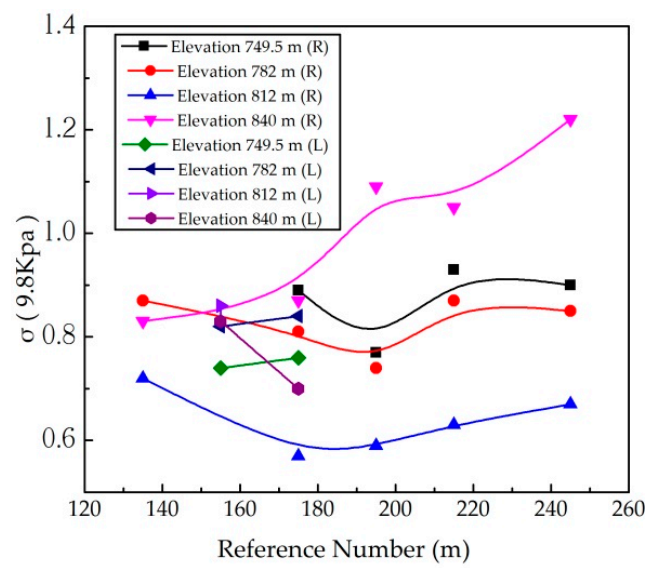

(a)

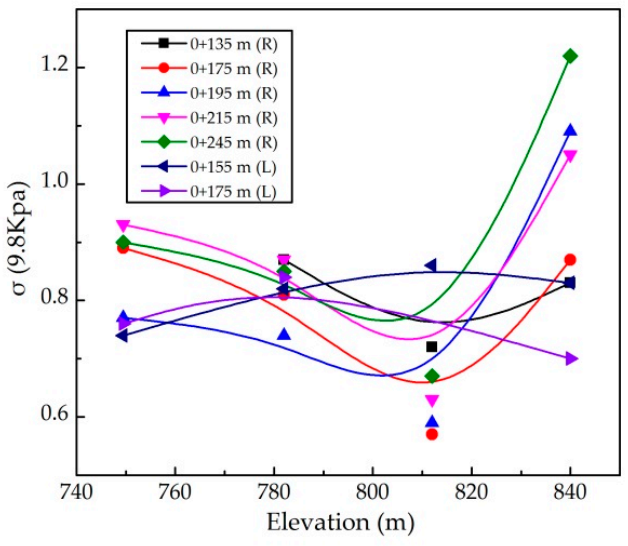

(b)

Figure 9. The RMS values $\sigma$ of fluctuating pressure histories on slope protection plates under operating Condition 2. (a) along reference numbers; and (b) along elevation.

The dominant frequencies of most fluctuating pressure histories range from 0 to $2 \mathrm{~Hz}$, which is consistent with the low frequency characteristics of the flow fluctuation. In some rare cases, the dominant frequencies range from 20 to $50 \mathrm{~Hz}$. The reason for very high dominant frequencies is considered to be the output distortion of sensors and interferences by electrical signal and other vibration signal.

\subsubsection{Reynolds Number for the Jet Exit Flow}

The experimental determination of flow velocity is very difficult, because the traditional instruments, such as the Pitot tube, the propeller flow meter and the acoustic Doppler current profile, generate disturbances in the original flow field so that the obtained flow velocities will not be very accurate. Moreover, the strong turbulence and the violent rolling of the flow significantly increase the difficulty of the measurement for the flow velocity. Therefore, the average jet exit velocity of the crest orifice can be calculated by the discharge of the outlet and the cross section of the orifice. As long as the reservoir water level remains unchanged, the flow velocity of the crest orifice jet exit is almost invariant. The hydraulic radius can be easily measured on the physical model, so the Reynolds number $(R e)$ can be obtained according to the formulation $R e=\rho \widetilde{u} L / \mu$, where parameters $\widetilde{u}, L$, and $\mu$ denote the average flow velocity of the section, the hydraulic radius, and the dynamic viscosity. It is calculated that the jet 
exit Reynolds number of the crest orifice is approximately 40,819. Moreover, the jet exit Reynolds number of the mid-level orifice can be calculated in a similar way. Due to the pressure flow discharged from the mid-level outlet, its hydraulic radius is the ratio between the cross-section area and the perimeter. The jet exit Reynolds number of the mid-level outlet is approximately 65,818 . Therefore, the effect of inertia force on the jet exit flow motion is much more significant the effect of viscous force.

\section{Determination of the Most Dangerous Slope Plate}

\subsection{Preliminary Analysis for the Failure Mechanism of the Slope Lining Plate}

In some cases of plunge pool floor failure, the fluctuating pressure propagates into cracks between the concrete slab and the bedrock when the waterstop fails, thus generating an uplift force that leads to the dislodging or structural failure of the lining. However, the slope protection structure is generally not directly affected by discharge jets, and based on the experimental results in Section 3.2.2, the fluctuating pressures acting on the slope lining plates were small. Therefore, the stress condition of the slope lining plate was different to that of the plunge pool floor plate, which meant that their failure mechanisms were also different.

Figure 10a shows the flow motion in the cracks between the bedrock and the drainage failure plates when the waterstop has partially failed and water can easily seep into the crack. In practice, there exists a possible adverse condition that the left, right, and bottom waterstops of the slope protection plate are intact, but the upper waterstop is damaged. As shown in Figure 10b, once the slope drainage system fails, the water continually seeps into the gap and cannot be drained quickly, thus, seepage pressure can be very large when the water level in the plunge pool drops rapidly. It is obvious that high seepage pressure is harmful to the stability of the slope protection plate, especially for plates in the violent fluctuation range of the water surface elevation. Recently, the slope lining plates in the plunge pool of a large hydropower project were seriously damaged due to a similar scenario. Therefore, research in the failure mechanism and structure optimization of the slope lining plates is of great practical significance.
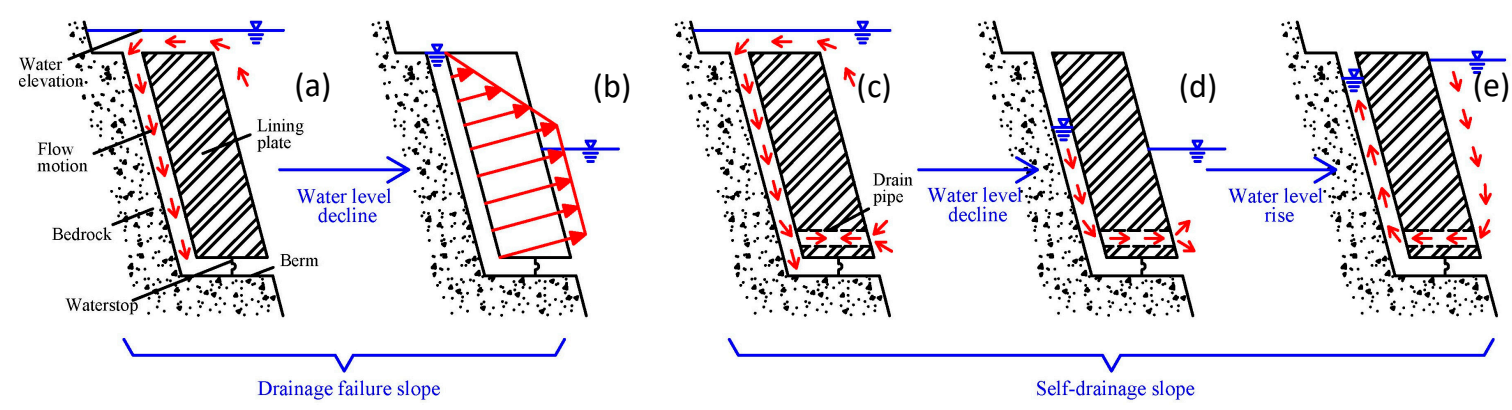

Figure 10. Motion of the flow inside the cracks between the lining plates and the bedrock. (a) drainage failure plate with high water level in plunge pool; (b) drainage failure plate with sudden drop of water level in plunge pool; (c) self-drainage plate with high water level in plunge pool; (d) self-drainage plate with sudden drop of water level in plunge pool; and (e) self-drainage plate with sudden rise of water level in plunge pool.

The stress state of the drainage failure slope plate under the most adverse working condition is illustrated in Figure 11. The anchoring force, plate gravity, and fluctuating pressure on the front surface were advantageous for the stability of the plate whereas the seepage pressure and fluctuating pressure on the back surface threatened plate safety. Due to poor connectivity between the gap and the pool, fluctuating pressures on the back and front sides of the slope lining plate can be regarded as two independent random processes that are generally considered to obey the normal distribution [10-12,24]. It was noted that the difference between the front and back fluctuating pressure histories may be quite large at a certain instant, therefore, the fluctuating difference may significantly contribute to slope 
plate destruction under certain conditions and should not be ignored without reasonable indication, despite seepage pressure generally considered to be more destructive.

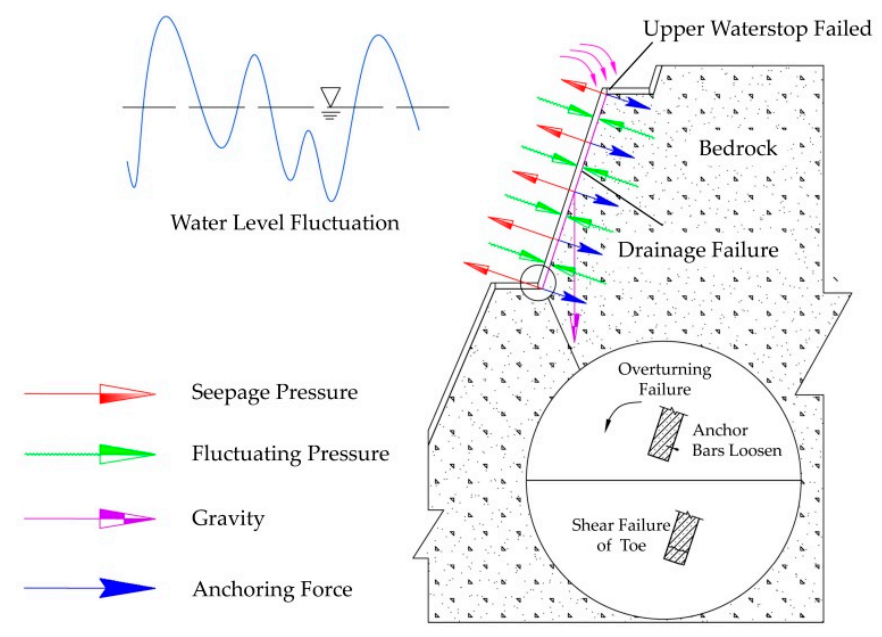

Figure 11. Schematic diagram for the stress state of drainage failure slope plate.

To ensure the operational safety of the slope lining plates, we proposed a self-drainage plate structure that could significantly increase the connectivity between the gap and the pool. Figure 10c-e illustrate the flow motion in the crack between the bedrock and the self-drainage plate under the most adverse condition (when the water level changes). Due to the existence of drain pipes, the water elevations in the crack and the pool will be much more balanced with a slight delay. Moreover, the fluctuating pressure on the front surface of the plate can also propagate to the back side through the drain pipes so that coherence is increased. Therefore, the pressure difference between the back and front sides of the plate can be effectively reduced and slope plate security improved. The performance of the proposed lining structure was verified under the most unfavorable operation condition (when the waterstops were partially invalid) as above-mentioned, and the detailed analysis is provided in subsequent sections.

\subsection{Experimental Scheme}

According to the above analysis, water will seep into the gap between the slope lining plate and bedrock through the invalid upper waterstop, but cannot be drained out of the gap due to the intact left, right, and bottom waterstops. Therefore, after a short period of flood discharge, the gap fills with water and in this case, pressure fluctuation can be transmitted into the gap and the water level in the crack is invariable. It was not difficult to conclude that the pressure difference between the back and front surfaces of the slope lining plate was mainly contributed by the seepage pressure and the aforementioned pressure fluctuation. As the water level was invariable in the gap, the operational safety of the slope lining plate was more difficult to guarantee in the violent fluctuation regions of the water surface elevation than in the region with relatively moderate water surface fluctuation, as the seepage pressure can be very large when the water level instantaneously drops to a large extent. Moreover, the wave action also has an adverse effect on the stability of the concrete slab. Experimental tests were conducted by Füehrboeter [40] to study the wave impact pressures on a flat and smooth slope where it was found that the probability distribution of the wave impact pressures obeyed log-normal functions and test results were on the safe side. Burger et al. [41] developed a semi-analytical, semi-empirical method to compute the loads on and the strength of a placed block revetment under perpendicular wave attack. Kirkgoz [42] studied the impact pressures, impact forces, and deflections from oscillatory waves breaking (by plunging) directly on vertical, $10^{\circ}$, and $30^{\circ}$ backward inclined walls with $110^{\circ}$ foreshore slope on the basis of physical model tests. Based on a 
wall deflection criterion, a range of water depth was determined where the wave breaking was likely to cause serious consequences on the wall. Neelamani et al. [43] presented simple prediction methods to estimate the wave induced pressures on smooth impermeable seawalls. Based on current research, the wave impact pressures will not cause instability to the slope lining plates that are firmly anchored on the bedrock.

To find out the most vulnerable plate and analyze its load condition in detail, we conducted a series of experiments to obtain the histories of water level fluctuations in the plunge pool. It was considered that the fluctuation intensity of the water surface increased with increasing flood discharge so only the two operational conditions listed in Table 2 were considered in the experiments to study the wave height distribution in the plunge pool. It is worth pointing out that the opening mode of the surface and mid-level orifices had a significant influence on the violent fluctuation region of the water surface in the plunge pool so that most vulnerable plate varied with different operation conditions. Due to less flood discharge under other working conditions, the maximum and mean wave height values in operating Conditions 1 and 2 should be larger than the values in other working conditions. The arrangement for the wave gauges in the plunge pool is illustrated in Figure 12 and the pressure sensors parameters including manufacturer, type, precision and other detailed performance factors are given in Figure 13.

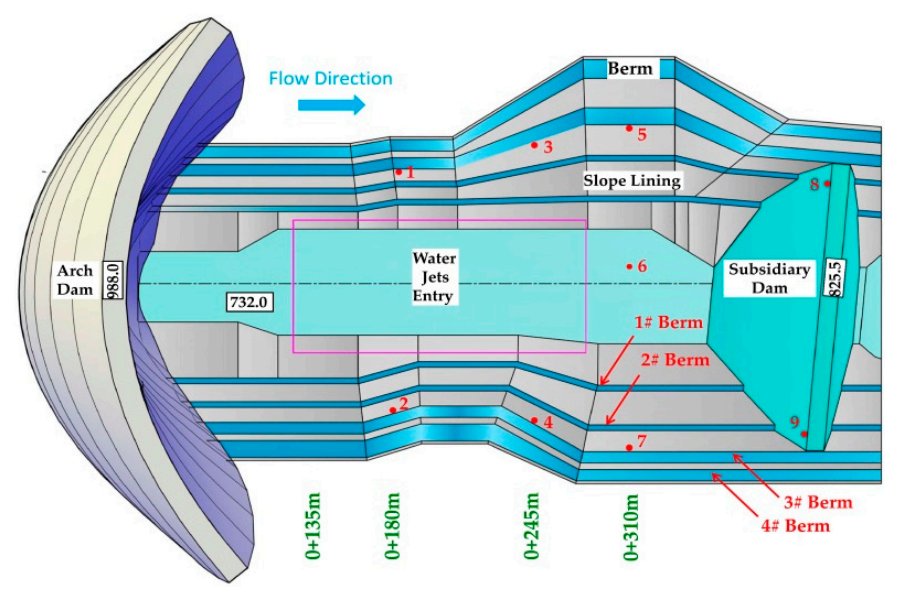

Figure 12. Arrangement of the wave height measuring points.

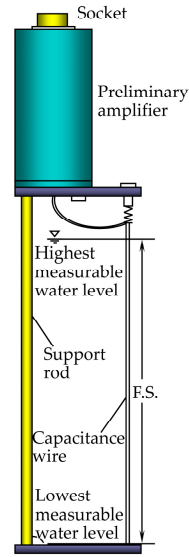

(a)

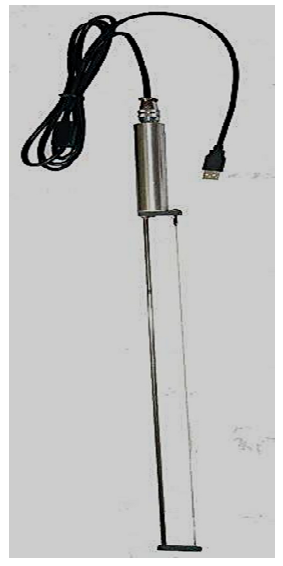

(b)
Manufacturer: China Institute of Water

Resources and Hydropower Research

Sensor type: Capacitive wave elevation gauge

Linearity error: $\leq \pm 0.5 \%$ F.S.

Water elevation measurement error: $\leq \pm 1 \%$ F.S.

Full-scale (F.S.): 0-0.6 m;

Response time: $\leq 1 \mathrm{~ms}$

Working temperature: $-10-40{ }^{\circ} \mathrm{C}$

Precision: $0.1 \mathrm{~mm}$

Acquisition frequency: $200 \mathrm{~Hz}$

Acquisition time: $100 \mathrm{~s}$

(c)

Figure 13. Constitution and performance parameters for the wave elevation gauge. (a) sensor components; (b) actual photograph; and (c) performance parameters. 


\subsection{Analysis for the Experimental Results}

For the Wudongde hydropower engineering, the crest elevation of its subsidiary dam is $825.5 \mathrm{~m}$, which is close to the elevation of the $3 \#$ berm $(827 \mathrm{~m})$. Therefore, it is understandable that the slope lining plates between the third and fourth berms are in the violent fluctuation region of the wave surface elevation according to the physical model experiments.

As shown in Figure 14, in operating Conditions 1 and 2, the mean and maximum values of the wave heights at different test points in the plunge pool increased with increasing reference numbers and reached the maximum when the reference number was approximately $0+310 \mathrm{~m}$, before decreasing with the increasing reference number. The mean and maximum wave elevation values near the right slope were larger than those near the left slope, which may have been caused by the difference between the shapes of the left and right slopes. As shown in Figure 12, the left bank expanded outwards sharply near the subsidiary dam, while the right bank remained straight along the flow direction in the reference number range from $0+300 \mathrm{~m}$ to $0+350 \mathrm{~m}$. Moreover, the variation trends of the maximum and mean wave height values were similar to each other.

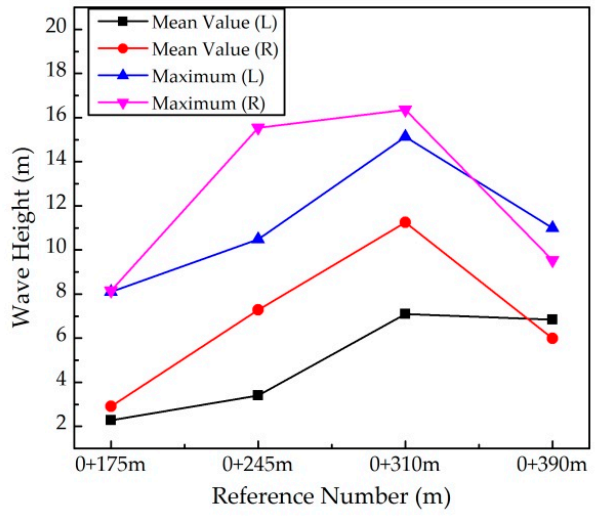

(a)

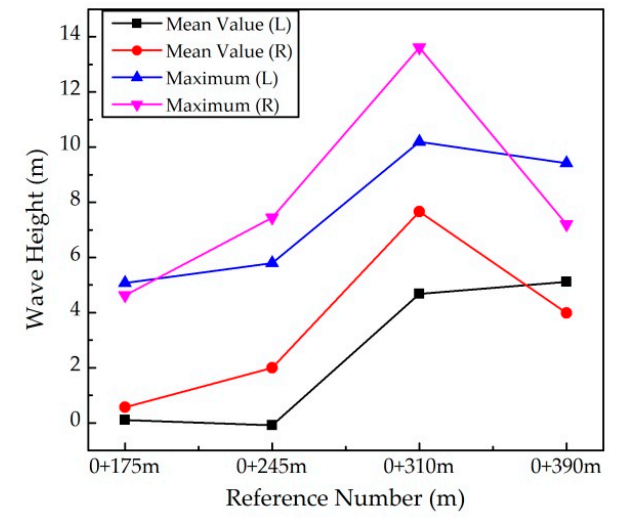

(b)

Figure 14. Mean and maximum wave height values along the reference numbers of both slopes under operating Conditions 1 and 2. (a) Condition 1; and (b) Condition 2.

According to the aforementioned experimental results, the slope lining plate on the right slope with the reference number $0+310 \mathrm{~m}$ was the most vulnerable plate as the water surface near this plate fluctuated more violently than near other plates under most working conditions. Therefore, the safety of this slope lining plate had more attention paid to it, and the loading condition of this lining plate in the possible adverse condition is analyzed in detail in the subsequent section.

\section{Experimental Research on the Loading Conditions of the Drainage Failure and Improved Slope Lining Plates}

\subsection{Experimental Scheme}

The lining plates above the third berm and close to the subsidiary dam were selected as the research object in the experimental work on the stress conditions of the drainage failure and improved slope lining plates; and the design and the dimensions of the improved self-drainage slope lining plates are given in Figure 15. Water-collecting grooves $(0.2 \mathrm{~m}$ wide $\times 0.2 \mathrm{~m}$ deep) were set on the back surfaces of the plate, and circular drain pipes with a diameter of $0.2 \mathrm{~m}$ were set at the bottom of the plate. Due to the different sizes of different plates on the slope of the Wudongde plunge pool, the parameters $L$ and $W$, which describe the distances between the grooves and drain pipes varied with different plates. Furthermore, the parameters $L$ and $W$ were approximately equal to $32 \mathrm{~m}$ and $12 \mathrm{~m}$ for the prototype scale, respectively. The detailed design and dimensions given in Figure 15 could 
serve as a reference for the plate design in practical engineering. In the model test, the only difference between the drainage failure plate and the illustrated plate structure was that the drain-pipes at the bottom of the plate were blocked. It is noted that 12 fluctuating pressure test points were arranged on the back and front surfaces of the lining plate.

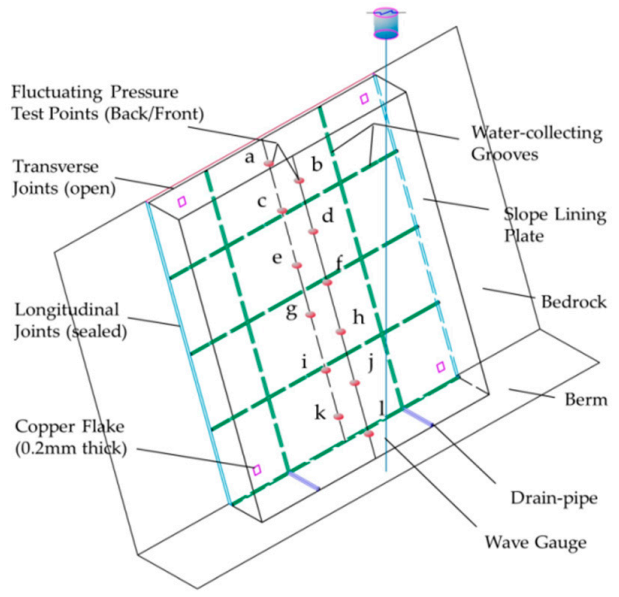

(a)

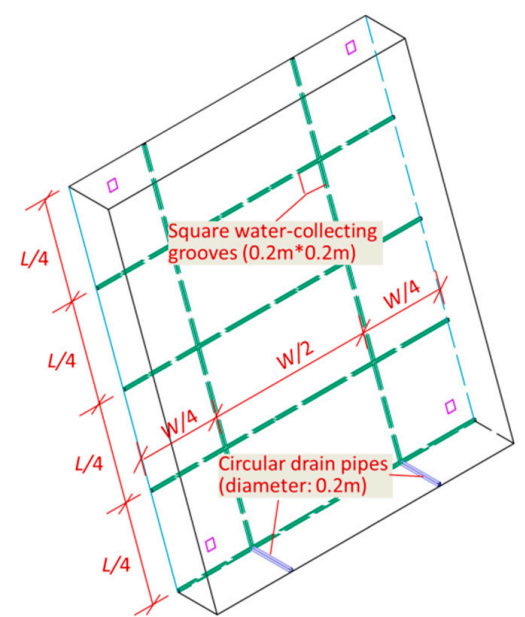

(b)

Figure 15. Structural design for the improved slope lining plate. (a) plate design; and (b) detailed physical dimension.

Hydraulic pressure histories were first collected at all 12 test points for about 20 different operating conditions. To avoid redundancy, the analysis of the experimental results of only two representative operating conditions (listed in Table 2) is given in the subsequent sections. Moreover, it should be pointed out that the variation law (drawn from the following analysis of the test results of the two representative operating conditions) was similar to the variation law drawn from a similar analysis for the experimental results under other conditions.

Considering the spatial variability of the hydraulic pressure, 12 hydraulic pressure test points were arranged on the back and front surfaces of the lining plate. Both fluctuating and time-average pressures are measured by the pressure sensors shown in Figure 5. It was difficult to quantitatively distinguish the pressures generated by the wave height and the pressures generated by the flow turbulence. We could approximately consider that the time-average pressure difference was caused by the time-average wave height difference between the gap and the pool. Moreover, the fluctuating pressure difference was considered to be mainly contributed by the wave height fluctuation and the flow turbulence. It was noted that the difference between the front and back fluctuating pressure histories may be quite large at certain instants, therefore, the fluctuating difference may significantly contribute to slope plate destruction under certain conditions and should not be ignored without reasonable indication, although seepage pressure is generally considered to be more destructive. In special cases, the calibration value of the pressure sensor changed during the experimental process. A feasible, but time-consuming method was to calibrate the transducers before and after a separate test. For every pressure sensor, the experimental results were believable if the two calibration values were almost equal to each other.

\subsection{Analysis for the Differences between the Fluctuating Pressures Measured on Back and Front Sides of the Slope Lining Plates}

For the drainage failure slope lining plate, the time history signals of the fluctuating pressures measured at the test points $e$ (back surface) and $f$ (front surface) are shown in Figure 16a. As the water continually seeps into the gap and cannot be rapidly drained out of the crack, the mean pressure on the back side of the plate was higher than that on the front side of the plate. Due to the poor connectivity 
between the gap and plunge pool for the drainage failure plate, the fluctuating pressure on the back side remained almost unchanged over time, which as fairly different from that on the front side.

For the self-drainage slope plate, the time history signals of the fluctuating pressures measured at test points $e$ (on the back side) and $f$ (on the front side) of the slope lining plate are illustrated in Figure $16 \mathrm{~b}$. Due to the limited capacity and time delay of the drainage, there was still little difference between the fluctuating pressures on the back and front surfaces. However, the stress conditions of the plate were improved on the whole, and the synchronism of the fluctuating pressures on the back and front sides of the protection plate was enhanced.

Figure 17 show the time history signals of the differences between the fluctuating pressures measured on the back and front sides of the drainage-failure and the self-drainage slope lining structures, respectively. The positive value indicated that the pressure on the plate tended to pull it away from the bedrock, and the negative value indicated that the force on the plate tended to press it towards the bedrock. This meant that the smaller the value, the safer the plate. The results showed that the maximum force per unit area of the drainage failure plate was $64.4 \mathrm{KPa}$, which seriously threatened the safety of the slope protection structure. By employing the self-drainage slope lining plate, the maximum force per unit area was significantly reduced to $20.1 \mathrm{KPa}$.

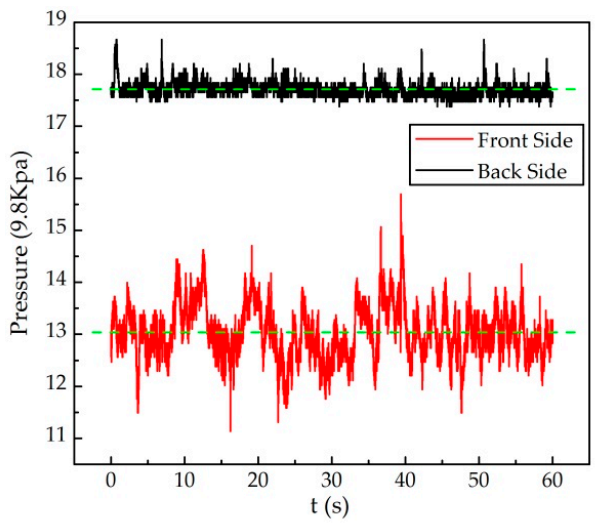

(a)

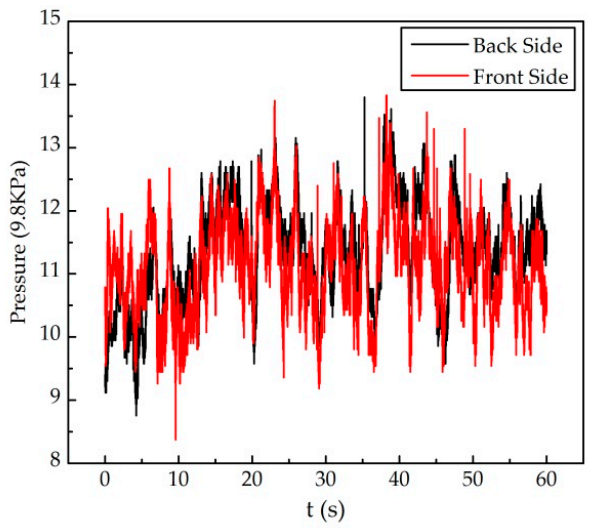

(b)

Figure 16. Hydraulic pressure histories measured at test points $e$ and $f$ under working Condition 1 . (a) drainage failure plate; and (b) self-drainage plate.

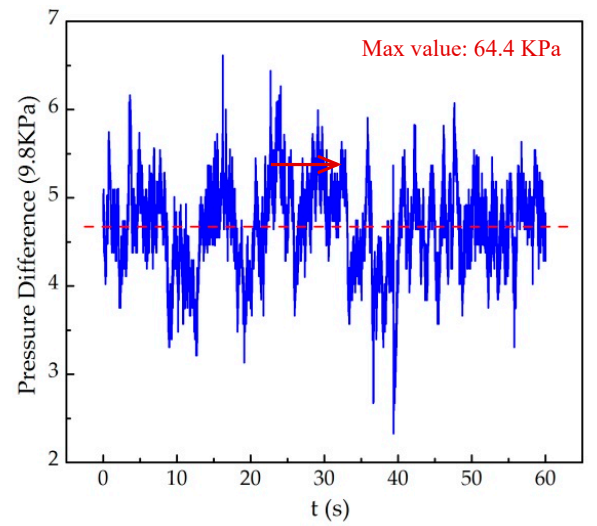

(a)

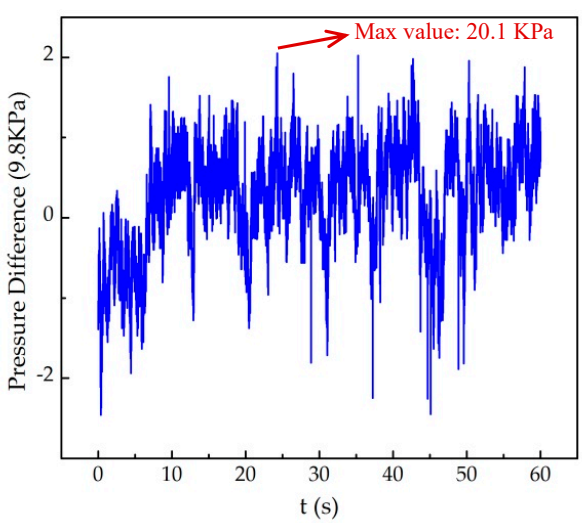

(b)

Figure 17. Time histories for the difference between the hydraulic pressures measured at test points $e$ and $f$ under working Condition 1. (a) drainage failure plate; and (b) self-drainage plate. 
Figure 18 shows the RMS and maximum values of difference histories between the fluctuating pressures measured at the test point pairs on different elevations. It can be seen that the RMS values for the self-drainage plate were generally smaller than values for the drainage failure plate. This meant that the synchronism of the fluctuating pressures on the back and front sides of the protection plate was enhanced and the hydraulic pressures on both sides of the lining slab were balanced as the connectivity between the water in the gap and the plunge pool was higher due to the unblocked drain-pipes as shown in Figure 15. As shown in Figure 18b, the maximum values at different elevations for the self-drainage plate were significantly less than the values for the drainage failure plate. One possible reason may be that seepage water could be rapidly drained out of the gap so that the seepage pressure was significantly reduced and the whole-time history curve moved downward in the coordinate system. Moreover, the increase of the synchronism between the fluctuating pressures on the back and front surfaces of the plate also contributed to the reduction of maximum value.

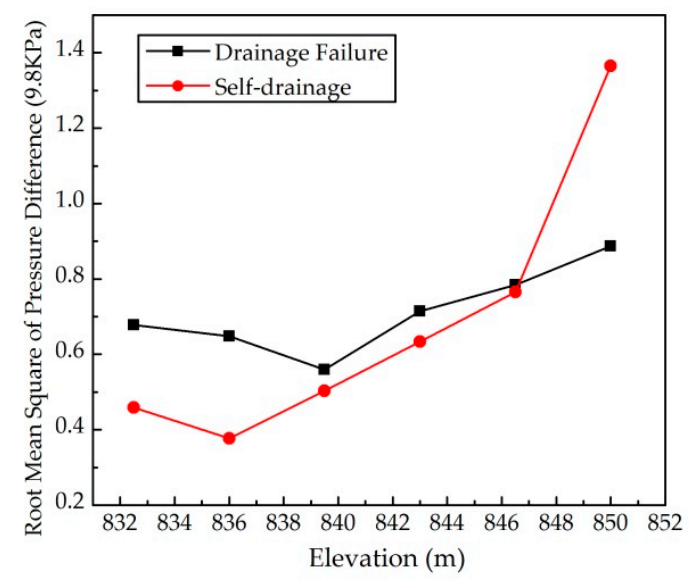

(a)

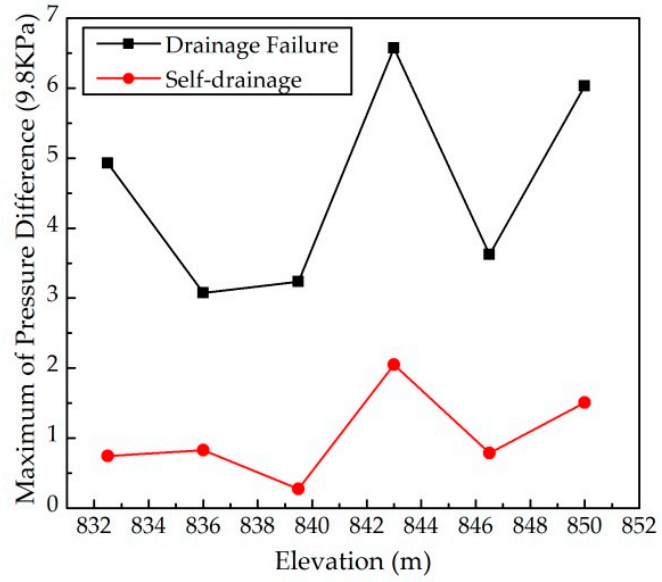

(b)

Figure 18. RMS and maximum values of the difference between the fluctuating pressure histories measured at test point pairs with different elevations for drainage failure and self-drainage plates.

(a) RMS values; and (b) maximum values.

The self-drainage slope lining plate will greatly improve the synchronization of fluctuating pressures on the front and back surfaces of the slope plate, rapidly drain the seepage water out of the gap between the lining plate and bedrock, and significantly reduce the difference between the hydraulic pressures on the aforementioned two surfaces, especially for the slope plate in the range of water surface fluctuations. Thus, the stability of the plate will be effectively improved.

\subsection{Correlation Analysis for the Fluctuating Pressures Measured on Back and Front Sides of the Slope Lining Plates}

\subsubsection{Correlation Theory}

Fluctuating pressure history is essentially a random process, thus its time autocorrelation function can be expressed as follows.

$$
R_{a}\left(t_{1}, t_{2}\right)=\int a_{1}\left(t_{1}\right) a_{2}\left(t_{2}\right) p^{\prime}\left(a_{1}, a_{2} ; t_{1}, t_{2}\right) d t_{1} d t_{2}
$$

where $R_{a}$ represents the time autocorrelation function of the random process $a_{;} t_{1}$ and $t_{2}$ denote two different moments; $a_{1}$ and $a_{2}$ denote the values of the stochastic process $a$ at time $t_{1}$ and $t_{2}$, respectively; and $p^{\prime}$ is the probability density function. 
Introducing another stochastic process into the above formula, the spatio-temporal cross-correlation function is obtained.

$$
R_{a b}\left(t_{1}, t_{2}\right)=\int a_{1}\left(t_{1}\right) b_{1}\left(t_{2}\right) p^{\prime}\left(a_{1}, b_{1} ; t_{1}, t_{2}\right) d t_{1} d t_{2}
$$

where $R_{a b}$ represents the spatio-temporal cross-correlation function of the random processes $a$ and $b$; and $b_{1}$ denotes the value of the random process $b$ at time $t_{2}$.

According to Equations (16) and (17), the cross-correlation coefficient $\rho$ between stochastic processes $a$ and $b$ as well as the corresponding time delay $\tau$ can be defined as:

$$
\begin{gathered}
\rho=\frac{R_{a b}\left(t_{1}, t_{2}\right)}{\sqrt{R_{a}\left(t_{1}, t_{2}\right) R_{b}\left(t_{1}, t_{2}\right)}} \\
\tau=t_{2}-t_{1}
\end{gathered}
$$

For the fluctuating pressure time histories measured at the test points on the back and front plate surfaces and with the same elevation and reference number, the time delays and the cross correlation coefficients can be calculated by Equations (16) to (19). The time delays reflect the phase difference of the two sets of signals, and the cross correlation coefficient was used to quantify the synchronization of the two signal histories. If the signals were completely synchronized, the cross correlation coefficient was 1 . Otherwise, the worse the signal synchronization, the closer the cross correlation coefficient to 0 . When $\tau=0$, the formula represents the instantaneous spatial correlation coefficient.

\subsubsection{Experimental Data Analysis}

Figure 19 shows the comparison of the correlations between hydraulic pressure histories measured at the test point pairs on different elevations for the drainage failure and self-drainage plates. It was noted that the two test points in every point pair were respectively arranged at the back and front surfaces of the slope lining plate.

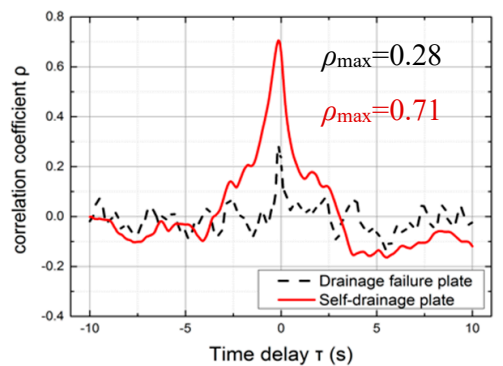

(a)

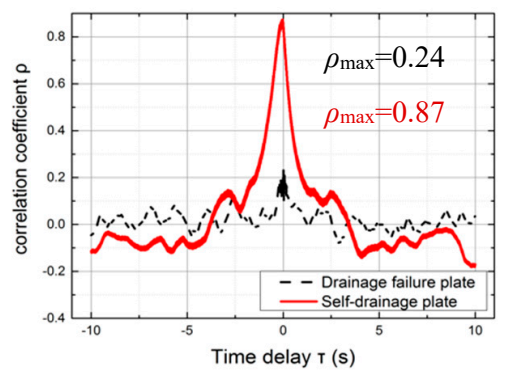

(d)

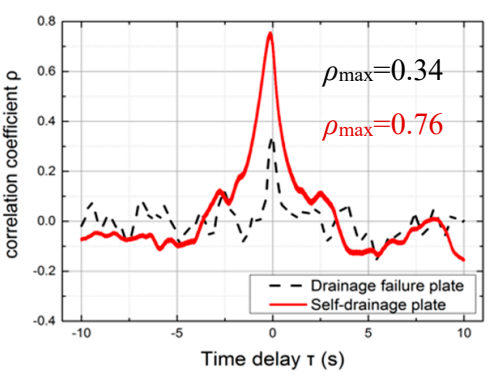

(b)

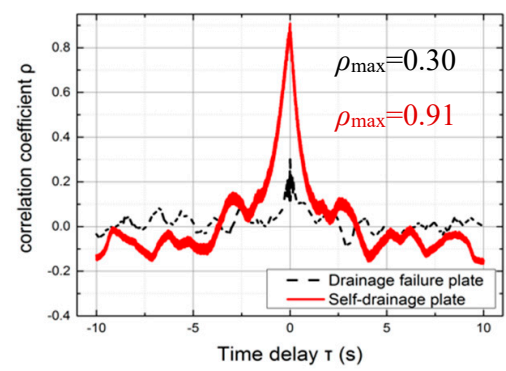

(e)

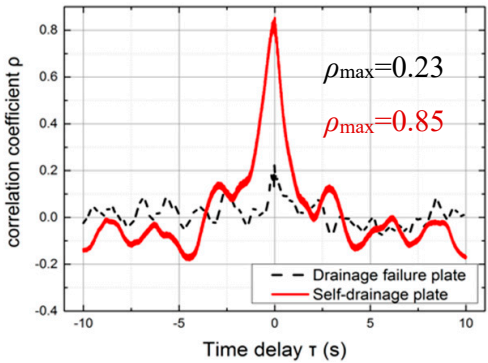

(c)

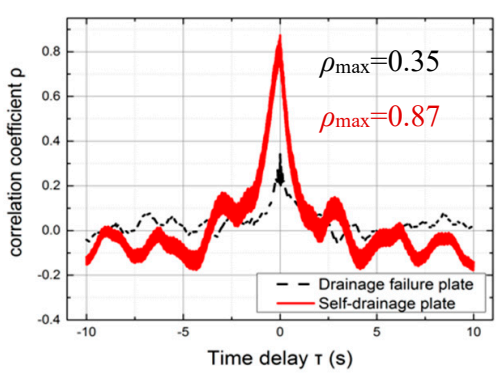

(f)

Figure 19. Comparison of the correlations between hydraulic pressure histories measured at the test point pairs on different elevations for the drainage failure and self-drainage plates. (a) Test point pair $a$, $b$; (b) Test point pair $c, d$; (c) Test point pair $e, f$; (d) Test point pair $g, h$; (e) Test point pair $i$, j; and (f) Test point pair $k, l$. 
Compared with the drainage failure slope, the self-drainage slope protection structure could improve synchronization between the fluctuating pressures on the front and back surface of the slope, especially for the test point in the fluctuation region of the wave surface elevation. For the drainage failure slope lining plate, the maximum values for the correlation coefficients illustrated in Figure 19a- $\mathrm{f}$ were similar to each other, and given the poor connectivity between the water in the gap and plunge pool, the correlation coefficient values were quite small. However, by applying the self-drainage slope lining structure, the cross correlation coefficients between the hydraulic pressure histories measured at the test point pairs at different elevations were significantly improved. Furthermore, it was noted that the maximum values of the correlation coefficients shown in Figure 19a-f decreased with increasing elevation, where the most likely reason was that the drain-pipes were equipped at the bottom of the plate so that the synchronism between the hydraulic pressure histories measured on the lower elevation was better than that at the higher elevation. Moreover, the time delay values for the hydraulic pressure histories measured at different test point pairs for both the drainage failure and self-drainage lining plates were all approximately equal to 0 , which indicated that the fluctuating pressure on the front surface of the plate was instantaneously transmitted to the back surface of the lining plate.

Although only the hydraulic loading condition for the slope lining plate on the right slope with the reference number $0+310 \mathrm{~m}$ under operating Condition 1 was measured and analyzed in the preceding sections, the stress conditions for other slope lining plates were also measured and considered many other working conditions. According to the comprehensive analysis for the stress conditions of all test plates under several operating conditions, the lining plate with reference number $0+310 \mathrm{~m}$ was the most vulnerable, and the self-drainage plate structure could always effectively reduce the total pressure on the slope plate.

\section{Conclusions}

In this paper, hydraulic pressures on the slope lining plates were analyzed according to the experimental results. The RMS values of fluctuating pressure histories on the slope increased with increasing flood discharge, and the maximum value was $15.29 \mathrm{KPa}$, which will not induce direct impact damage to the slope plate. Experimental results showed that the hydraulic loads on the front surfaces of the slope protection plates were quite small; however, under possible adverse working conditions, the high seepage pressure on the back surface of slope lining plate and the poor correlation between the fluctuating pressures on the back and front plate surfaces will cause a large pressure difference, which seriously threatens the operational safety of the slope lining plate.

The experimental research on the water surface elevation in the plunge pool was carried out to find the most vulnerable slope lining plate. According to the experimental results, the elevation of the water surface near the lining plate on the right slope with reference number $0+310 \mathrm{~m}$ fluctuated more violently than the elevation of the water surface near other lining plates. Therefore, the stress condition of this slope lining plate was measured and analyzed in detail.

A self-drainage slope protection structure was proposed for slope load reduction. The most adverse operating conditions (when the drainage system was invalid and the waterstops were partially damaged) were considered in the experiments. The coupling analyses of the hydraulic pressure on the back and front sides of the slope plate were carried out. Compared with the drainage failure slope, the self-drainage slope protection could effectively enhance the synchronism of the fluctuating pressures on the back and front surfaces of the slope plates and significantly balance the hydraulic pressures on both surfaces.

Moreover, a correlation analysis for the fluctuating pressures measured on the back and front surfaces of the slope lining plates was carried out. It was noted that the maximum correlation coefficients between the fluctuating pressure histories measured at the test point pairs near the drain-pipes were larger than other correlation coefficients, which conforms to the actual situation and partially verifies the reliability of the experiments. 
Acknowledgments: The paper was supported by the National Key R\&D Program of China (2016YFC0401705), the Science Fund for Creative Research Groups of the National Natural Science Foundation of China (51621092), the National Natural Science Foundation of China (51779167, 51309177, 51509180, and 51579173), and the Program of Introducing Talents of Discipline to Universities (B14012). Anonymous reviewers are acknowledged for their assistance.

Author Contributions: The model test was conceived and designed by Bin Ma, providing guides in detail; the experiments were conducted by Chao Liang, Shuai Liang, and Yijia Li; Chao Liang contributed to data analysis; all authors prepared the manuscript.

Conflicts of Interest: The authors declare no conflict of interest.

\section{Appendix A}

Table A1. All of the flood discharge operating conditions involved in the model tests.

\begin{tabular}{|c|c|c|c|c|c|}
\hline \multirow[b]{2}{*}{ Case } & \multirow[b]{2}{*}{ Upstream Water Level (m) } & \multirow[b]{2}{*}{ Flood Discharged from Dam Body $\left(\mathrm{m}^{3} / \mathrm{s}\right)$} & \multirow[b]{2}{*}{ Downstream Water Level (m) } & \multicolumn{2}{|c|}{ Opening Outlets } \\
\hline & & & & Surface Outlets & Mid-Level Outlets \\
\hline 1 & 979.38 & $20,186.0$ & 849.73 & 1\#2\#3\#4\#5\# & 1\#2\#3\#4\#5\#6\# \\
\hline 2 & 975 & $16,421.5$ & 847.86 & 1\#2\#3\#4\#5\# & $1 \# 2 \# 3 \# 4 \# 5 \# 6 \#$ \\
\hline 3 & 975 & 13,371 & 834.0645 & 1\#2\#3\#4\#5\# & 2\#3\#4\#5\# \\
\hline 4 & 975 & $13,513.5$ & 834.1936 & 2\#3\#4\# & 1\#2\#3\#4\#5\#6\# \\
\hline 5 & 975 & 4504.5 & 822.7045 & 3\# & $3 \# 4 \#$ \\
\hline 6 & 975 & 7412.5 & 827.3818 & $2 \# 3 \# 4 \#$ & 3\#4\# \\
\hline 7 & 975 & 10463 & 831.1811 & 2\#3\#4\# & 2\#3\#4\#5\# \\
\hline 8 & 975 & 7270 & 827.1892 & 1\#2\#3\#4\#5\# & $\backslash$ \\
\hline 9 & 975 & 1454 & 816.1688 & 3\# & 1 \\
\hline 10 & 975 & 4362 & 822.45 & $2 \# 3 \# 4 \#$ & 1 \\
\hline 11 & 975 & 9151.5 & 829.6814 & $\backslash$ & $1 \# 2 \# 3 \# 4 \# 5 \# 6 \#$ \\
\hline 12 & 975 & 3050.5 & 820.0394 & 1 & 3\#4\# \\
\hline 13 & 975 & 3050.5 & 820.0394 & 1 & 2\#5\# \\
\hline 14 & 975 & 3050.5 & 820.0394 & 1 & $1 \# 6 \#$ \\
\hline 15 & 975 & 6101 & 825.4517 & 1 & $2 \# 3 \# 4 \# 5 \#$ \\
\hline 16 & 975 & 1454 & 816.1688 & $4 \#$ & $\backslash$ \\
\hline 17 & 975 & 2908 & 819.7289 & $4 \# 5 \#$ & 1 \\
\hline 18 & 975 & 1525.25 & 816.3914 & $\backslash$ & $4 \#$ \\
\hline 19 & 975 & 3050.5 & 820.0394 & 1 & $4 \# 5 \#$ \\
\hline 20 & 975 & 4575.75 & 822.8317 & 1 & 4\#5\#6\# \\
\hline
\end{tabular}

\section{References}

1. Sanchez Bribiesca, J.S.; Capella Viscaino, A.C. Experimental analysis of Macroturbulence effects on the lining of stilling basins. In Proceedings of the 11th International Congress on Large Dams, Madrid, Spain, January 1979.

2. Bowers, C.E.; Toso, J. Karnafuli project, model studies of spillway damage. J. Hydraul. Eng. 1988, 114, 469-483. [CrossRef]

3. Bowers, C.E.; Toso, J. Closure to "Karnafuli project, model studies of spillway damage" by C. Edward Bowers and Joel Toso (May, 1988, Vol. 114, No. 5). J. Hydraul. Eng. 1990, 116, 854-855. [CrossRef]

4. Fiorotto, V.; Rinaldo, A. Discussion of Karnafuli project, model studies of spillway damage by C.E. Browers and J Toso. J. Hydraul. Eng. 1990, 116, 850-852. [CrossRef]

5. Smith, C.D. Discussion of Karnafuli project, model studies of spillway damage by C.E. Browers and J. Toso. J. Hydraul. Eng. 1990, 116, 852-853. [CrossRef]

6. Liu, P.Q.; Liu, X.A.; Li, F.T. Failure mechanism of bottom plate in stilling basin and countermeasure for protection. J. Hydraul. Eng. 2001, 9, 1-9.

7. Melo, J.F.; Pinheiro, A.N.; Ramos, C.M. Forces on plunge pool slabs: Influence of joints location and width. J. Hydraul. Eng. 2006, 132, 49-60. [CrossRef]

8. Liu, P.Q.; Li, A.H. Model discussion of pressure fluctuations propagation within lining slab joints in stilling basins. J. Hydraul. Eng. 2007, 133, 618-624.

9. Rehbinder, G. Slot cutting in rock with a high speed a water jet. Rock Mech. Min. Sci. 1977, 14, $229-234$. [CrossRef]

10. Zhao, Y.N.; Liang, X.R. Investigation on fluctuating pressure transmission along joints. J. Tianjin Univ. Sci. Technol. 1988, 3, 55-65. (In Chinese)

11. Li, A.H.; Zhu, J.; Li, C.H. Further discussion on propagation model of fluctuating pressure within cracks. J. Hydraul. Eng. 2015, 46, 626-630. 
12. Liu, P.Q.; Deng, X.Y. Numerical investigation of pressure fluctuations within crack layers of lower surfaces of slabs. Acta Mech. Sin. 1998, 30, 662-671. (In Chinese)

13. Sun, J.; Zhang, C.C.; Feng, X.L.; Hao, X.L.; Zhang, F.M. Comparison of flow fields of the arch inverted plunge cushion pool with the flat-bottomed cushion pool of Xiluodo arch dam by using 3-D numerical simulation. J. Sichuan Univ. Eng. Sci. Ed. 2009, 41, 8-11. (In Chinese)

14. Fiorotto, V.; Barjastehmaleki, S.; Caroni, E. Stability analysis of plunge pool linings. J. Hydraul. Eng. 2016, 142, 1-11. [CrossRef]

15. Lian, J.J.; Liu, X.Z.; Ma, B. Safety evaluation and the static-dynamic coupling analysis of counter-arched slab in plunge pool. Sci. China Ser. E 2009, 52,1-16. [CrossRef]

16. Yang, M.; Dong, T.S. Research progress in stability of protecting structure in high dam plunge pool. J. Changchun Inst. Technol. Nat. Sci. Ed. 2010, 11, 77-81. (In Chinese)

17. Yang, M.; Li, S.N. Experimental investigation of fluctuating pressure acting on the undersurface of pervious slabs in flat-bottom plunge pool. J. Hydraul. Eng. 2011, 42, 1368-1371.

18. Zhang, S.J.; Yang, M. Experimental study on characteristics of pressure fluctuations on the pervious bottom slab of a plunge pool. J. Hydroelectr. Eng. 2010, 29, 85-89, 94. (In Chinese)

19. Ma, B.; Lian, J.J.; Liu, X.Z. Safety analysis on bottom slab of plunge pool with key grooves. Water Resour. Hydropower Eng. 2009, 40, 66-70. (In Chinese)

20. Ma, B.; Yue, Y. Research on characteristics of fluctuating pressure in the gap on special-shaped slab of plunge pool. J. Tianjin Univ. Sci. Technol. 2016, 49, 96-102. (In Chinese)

21. Castillo, L.G.; Carrillo, J.M. Scour, Velocities and Pressures Evaluations Produced by Spillway and Outlets of Dam. Water. 2016, 8, 68. [CrossRef]

22. Yang, M. Study on Hydrodynamic Characteristics and Safety of Protecting Structure in High Dam Plunge Pool. Ph.D. Thesis, Tianjin University, Tianjin, China, June 2003. (In Chinese)

23. Xu, G.B.; Yin, W.B.; Lian, J.J.; Peng, X.M. Model test on cushion pool with lining slope but no bottom protection in Nuozhadu hydraulic power station. J. Yangtze River Sci. Res. Inst. 2007, 24, 1-4, 15. (In Chinese)

24. Sun, J.; Li, Y.Z.; Yu, C.C. Experimental research on the cushion pool with lining slope but no bottom protection in Xiaowan project. Water Resour. Hydropower Eng. 2001, 32, 52-56. (In Chinese)

25. Sun, S.K.; Liu, H.T.; Sun, T.B. Study on the layout of flood discharge and energy dissipation of high arch dam within deep overburden layers. J. Hydroelectr. Eng. 2010, 29, 26-30. (In Chinese)

26. Liu, P.Q.; Li, A.H. Fluctuating uplift acting on rock blocks at the bottom of river bed and estimation of the limiting scour depth. J. Hydraul. Res. 2007, 45, 478-485.

27. Liu, F. Study on Characteristics of Fluctuating Wall-pressure and Its Similarity Law. Ph.D. Thesis, Tianjin University, Tianjin, China, May 2007. (In Chinese)

28. Rehbinder, G. A theory about cutting rock with a water jet. Rock Mech. 1980, 12, 247-257. [CrossRef]

29. Fiorotto, V.; Rinaldo, R. Fluctuating uplift and lining design in spillway stilling. J. Hydraul. Eng. ASCE 1992, 118, 578-596. [CrossRef]

30. Liu, P.Q.; Dong, J.R.; Yu, C. Experimental investigation of fluctuating uplift on rock blocks at the bottom of the scour pool downstream of Three-Gorges spillway. J. Hydraul. Res. 1998, 36, 55-68. [CrossRef]

31. Manso, P.A.; Bollaert, E.F.R.; Schleiss, A.J. Influence of Plunge Pool Geometry on High-Velocity Jet Impact Pressures and Pressure Propagation inside Fissured Rock Media. J. Hydraul. Eng. 2009, 135, 783-792. [CrossRef]

32. Ervine, D.A.; Falvey, H.T. Behaviour of Turbulent Water Jets in the Atmosphere and in Plunge Pools. Proc. Inst. Civ. Eng. 1987, 83, 295-314. [CrossRef]

33. Ervine, D.A.; Falvey, H.T.; Withers, W.A. Pressure fluctuations on plunge pool floors. J. Hydraul. Res. 1997, 35, 257-279. [CrossRef]

34. Bollaert, E.F.R.; Schleiss, A.J. Scour of rock due to the impact of plunging high velocity jets Part I: A state-of the-art review. J. Hydraul. Res. 2003, 41, 451-464. [CrossRef]

35. Bollaert, E.F.R.; Schleiss, A.J. Scour of rock due to the impact of plunging high velocity jets Part II: Experimental results of dynamic pressures at pool bottoms and in one- and two-dimensional closed end rock joints. J. Hydraul. Res. 2003, 41, 465-480. [CrossRef]

36. Manso, P.A.; Bollaert, E.F.R.; Schleiss, A.J. Evaluation of high-velocity plunging jet-issuing characteristics as a basis for plunge pool analysis. J. Hydraul. Res. 2008, 46, 147-157. [CrossRef] 
37. Castillo, L.G.; Carrillo, J.M. Analysis of the scale ratio in nappe flow case by means of CFD numerical simulation. In Proceedings of the 2013 IAHR Congress, Chengdu, China, 8-13 September 2013.

38. Castillo, L.G.; Carrillo, J.M.; Blázquez, A. Plunge pool mean dynamic pressures: A temporal analysis in nappe flow case. J. Hydraul. Res. 2014, 53, 101-118. [CrossRef]

39. Castillo, L.G.; Carrillo, J.M.; Bombardelli, F.A. Distribution of mean flow and turbulence statistics in plunge pools. J. Hydroinform. 2017, 19, 173-190. [CrossRef]

40. Füehrboeter, A. Model and prototype test for wave impact and rub-up on a uniform 1:4 slope. Coast. Eng. 1986, 10, 49-84. [CrossRef]

41. Burger, A.M.; Breteler, M.K.; Banach, L.; Bezuijen, A.; Pilarczyk, K.W. Simplified design method for block revetments. J. Waterway Port Coast. Ocean Eng. 1990, 116, 525-544. [CrossRef]

42. Kirkgoz, M.S. Influence of water depth on the breaking wave impact on vertical and sloping walls. Coast. Eng. 1992, 18, 297-314. [CrossRef]

43. Neelamani, S.; Schüttrumpf, H.; Muttray, M.; Oumeraci, H. Prediction of wave pressures on smooth impermeable seawalls. Ocean Eng. 1999, 26, 739-765. [CrossRef]

(C) 2017 by the authors. Licensee MDPI, Basel, Switzerland. This article is an open access article distributed under the terms and conditions of the Creative Commons Attribution (CC BY) license (http:/ / creativecommons.org/licenses/by/4.0/). 